\title{
Nanoformulations of curcumin: an emerging paradigm for improved remedial application
}

\author{
Meeta Gera ${ }^{1, *}$, Neelesh Sharma ${ }^{2, *}$, Mrinmoy Ghosh ${ }^{1}$, Do Luong Huynh ${ }^{1}$, Sung Jin \\ Lee $^{3}$, Taesun Min ${ }^{1}$, Taeho Kwon ${ }^{1,4}$ and Dong Kee Jeong ${ }^{1,4}$ \\ ${ }^{1}$ Department of Animal Biotechnology, Faculty of Biotechnology, Jeju National University, Jeju, Republic of Korea \\ ${ }^{2}$ Division of Veterinary Medicine, Faculty of Veterinary Science and Animal Husbandry, Sher-e-Kashmi University of Agricultural \\ Sciences and Technology, R.S. Pura, Jammu, India \\ ${ }^{3}$ Department of Animal Biotechnology, College of Animal Bioscience and Technology, Kangwon National University, Gangwon-do, \\ Republic of Korea \\ ${ }^{4}$ Laboratory of Animal Genetic Engineering and Stem Cell Biology, Subtropical/Tropical Organism Gene Bank, Jeju National \\ University, Jeju, Republic of Korea \\ *These authors contributed equally to this work
}

Correspondence to: Dong Kee Jeong, email: ngejeong@gmail.com, dkjeong@jejunu.ac.kr Taeho Kwon, email: taehokwonk@gmail.com

Keywords: curcumin, herb, nano, nanoformulation, nanotechnology

Received: May 26, $2017 \quad$ Accepted: June 29, $2017 \quad$ Published: July 11, 2017

Copyright: Gera et al. This is an open-access article distributed under the terms of the Creative Commons Attribution License 3.0 (CC BY 3.0), which permits unrestricted use, distribution, and reproduction in any medium, provided the original author and source are credited.

\section{ABSTRACT}

Curcumin is a natural polyphenol and essential curcuminoid derived from the rhizome of the medicinal plant Curcuma longa ( $L$.$) is universally acknowledged as "Wonder drug$ of life". It is a vital consumable and restorative herb, commonly keened for several ailments such as cancer, arthritis, pain, bruises, gastrointestinal quandaries, swelling and much more. Despite its enormous curative potential, the poor aqueous solubility and consequently, minimal systemic bioavailability with rapid degradation are some of the major factors which restrict the utilization of curcumin at medical perspective. However, to improve its clinically relevant parameters, nanoformulation of curcumin is emerging as a novel substitute for their superior therapeutic modality. It enhances its aqueous solubility and targeted delivery to the tissue of interest that prompts to enhance the bioavailability, better drug conveyance, and more expeditious treatment. Subsequent investigations are endeavored to enhance the bio-distribution of native curcumin by modifying with felicitous nano-carriers for encapsulation. In this review, we specifically focus on the recent nanotechnology based implementations applied for overcoming the innate constraints of native curcumin and additionally the associated challenges which restrict its potential therapeutic applications both in vivo and in-vitro studies, as well as their detailed mechanism of action, have additionally been discussed.

\section{INTRODUCTION}

Since archaic times, people around the world have been harnessing the natural sources for various medicinal purposes. With the passage of time, the curiosity to explore the medicinal benefits of natural habitat is being increased and has now become one of the prime areas of scientific research $[1,2]$. Curcuma longa (Linn.) commonly kenned as turmeric, belongs to Zingiberaceae family and is widely utilized as an ingredient spice $[3,4]$. The history of Curcuma longa (Linn.) dates back over antediluvian time of Ayurveda, commonly found in tropical, sub-tropical and Southeast regions are widely cultivated areas for use as an ingredient spice (Figure 1). Among a large number of components isolated from turmeric, Curcumin was found to be the most active polyphenol extracted and evidenced by enormous citations in the literature so far [5]. The structure of 
curcumin $\left(\mathrm{C}_{21} \mathrm{H}_{20} \mathrm{O}_{6}\right)$ is also known as diferuloylmethane and first identified by Lampe and Milobedeska in 1910 (Figure 2) [6]. The IUPAC nomenclature of curcumin is 1, 7-bis (4-hydroxy-3-methoxy phenyl)-1, 6-heptadiene-3, 5-dione (1E-6E) consisting of two aryl rings containing ortho-methoxy phenolic $\mathrm{OH}^{-}$groups are symmetrically linked to a $\beta$-diketone moiety. The unique polyphenol compound comprises of heptadiene-dione moiety was observed in curcumin with a molecular mass of $368.37 \mathrm{~g} /$ mole and melting temperature of $183^{\circ} \mathrm{C}$ [7]. Curcumin contains two para hydroxyl groups, keto groups, methoxy groups, an active methylene group [8]. However the solution of curcumin have enol group while it is more stable in keto form [9]. Curcumin is a hydrophobic, polyphenolic compound, hence insoluble in water at acidic and neutral $\mathrm{pH}$ conditions, however soluble in methanol, ethanol, dimethylsulfoxide, and acetone [10] with a melting point at $176^{\circ} \mathrm{C} \pm 2$. Curcumin exhibits widespread applications such as antioxidant [11, 12], anti-cancer [13], anti-arthritic, anti-microbial [14] antidiabetic [15] and anti-inflammatory activities [16] and avails in the treatment of many ailments including tendinitis, liver cirrhosis, Alzheimer's disease, heart attack, hypoglycemia, gastrointestinal problems, worms, swelling, cancer, skin and ocular perceiver infections (Figure 3) [17, 18]. However, the native curcumin is associated with some major drawbacks such as poor absorption, low bioavailability, high metabolic rates and rapid excretion from the body. Hence, in spite of having multidisciplinary medicinal benefits, turmeric has not yet been considered commercially as a potent therapeutic agent.

Despite a century of perpetual research innovations and efforts have aimed to surmount the obstacles of native curcumin, the incursion of nanoparticle formulations may act as a "magic bullet" which rationally incorporated a paradigmatic shift for treating a wide range of chronic diseases utilizing nano-curcumin through efficacious drug distribution process. The numerous studies address the development and in vitro evaluation of nano-curcumin that is intended for site-specific delivery of curcumin with high permeability, longer circulation and increased biodistribution which brings significant efficacious responses [19]. Therefore, to enhance the same, various nanoparticle-based approaches have also been sought, such as encapsulation in liposomes [20], chitosan [21], and solid-lipid microparticles based technique utilizing bovine serum albumin [22] to negotiate the various impediments such as poor absorption rate, low bio-availability, and distribution, targeted delivery to the affected tissue of interest which limits its felicitous therapeutic translation. Patra et al., designed a dual (magnetic and thermal)responsive nanoparticles using advanced nano innovative applications for effective delivery and enhanced efficacy of curcumin [23]. The intranasal administration also identified as a novel nanotechnology based delivery brings about enhancing the bioavailability of curcumin [24].

This observation has led to the lower absorption and poor bio-distribution of native curcuminof medicine holds considerable promise and can resolve these major

$\underline{\text { Turmeric (Curcuma longa L.) }}$

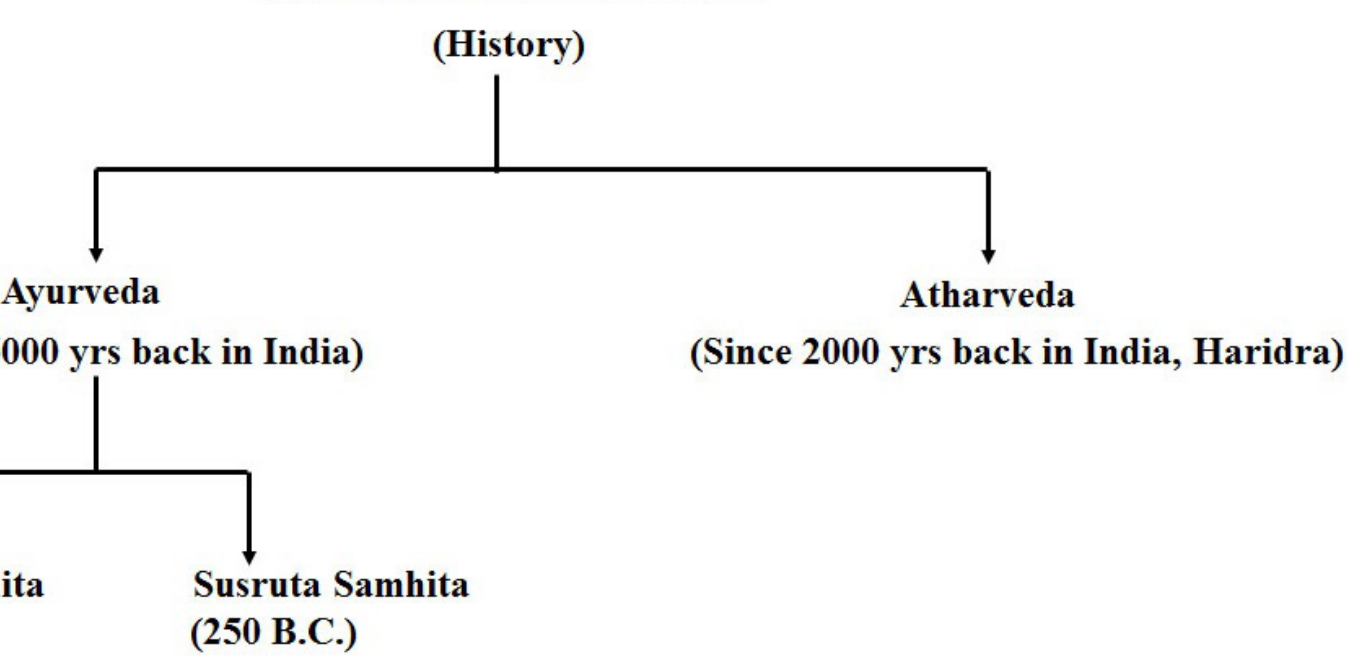

(Advent of Turmeric as traditional medicine)

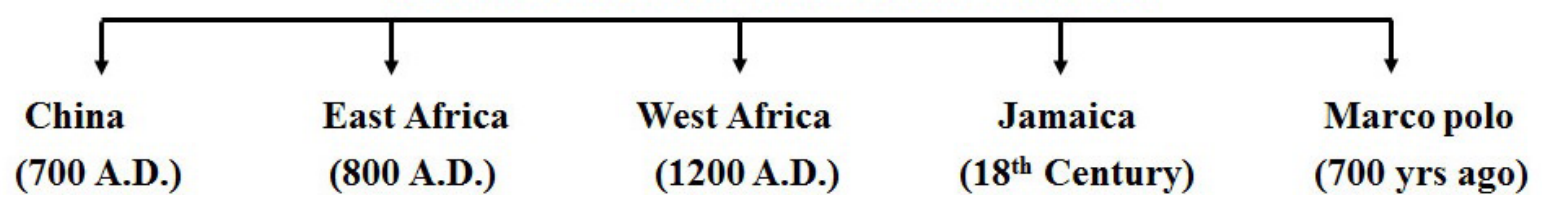

Figure 1: Historical background of Curcumin. 
challenges. To explore its therapeutic potential and to get a molecular insight of the same, nearly 3000 preclinical studies have been conducted that make the consideration of curcumin and its derivatives as one of the most thoroughly investigated and developed natural remedy [25]. This review summarizes the recent investigations on the potential efficacy of curcumin, various nanotechnology-based tools applied for overcoming the limitations and their marked amendments in its restorative utilizations such as anti-oxidant, anti-inflammatory properties, and more concretely anti-cancerous properties. In addition to this, substantial challenges associated with native curcumin which obstructs its clinical translation are additionally discussed.

\section{Challenges associated with native curcumin as therapeutic agent}

The native curcumin has proven to offer enormous therapeutic applications including anti-oxidant $[11,12]$, anti-carcinogenic [13], anti-microbial [14], anti-diabetic [15] and anti-inflammatory [16], but the utility of curcumin is greatly hindered due to some of its major associated challenges like poor absorption, low bioavailability, rapid systemic elimination and high metabolism inhibiting their therapeutic action. It is noteworthy that curcumin has poor aqueous solubility of about $11 \mathrm{ng} / \mathrm{ml} \mathrm{[26]} \mathrm{and}$ undergoes degradation in alkaline conditions. At $\mathrm{pH}<7$, the degradation of curcumin is much slower, with less than $20 \%$ of total curcumin decomposed at $1 \mathrm{hr}[27,28]$. To overcome these major issues, a substantial amount of dosage need to be administered, which reduces its supplemental utilization $[29,30]$.

Shehzad and his coworkers studied that the oral administration of native curcumin leads to $40 \%$ of excretion in the faeces. In addition, in aqueous solution and at neutral $\mathrm{pH}$, curcumin undergoes degradation which might contribute to its short half-life, which is reported to be 28.1 \pm 5.6 and $44 \pm 7.5 \mathrm{~h}$ in the rat for an intravenous dose of $10 \mathrm{mg} / \mathrm{kg}$ and an oral dose of $500 \mathrm{mg} / \mathrm{kg}$, respectively [31].
Wahlstrom and Blennow gave the first report by examining the bio-distribution, cellular uptake and excretion of curcumin in Sprague-Dawley rats. Their results concluded that after oral administration of native curcumin at very high amount of dose of about $1 \mathrm{~g} / \mathrm{kg}$ in rats, $75 \%$ of which was excreted out in the faeces. They also suggested that only meager amounts of native curcumin were found in the blood plasma levels of rats showed that the native curcumin was poorly absorbed from the gut [32]. The plausible reason of low bioavailability may also be the high metabolic rates thereby reducing bio-distribution as it was also reported that Liver is the major organ involved in the metabolism of curcumin, which undergoes conjugations like glucuronides of Tetrahydrocurcumin (THC) and Hexahydrocurcumin (HHC) in rats [33]. It was also reported that a very small portion of curcumin has been absorbed in intestine which suffered a rapid metabolism in the liver and plasma. Curcumin is extensively converted to its water-soluble metabolites (glucuronides and sulfates) and excreted through urine [34-35]. The administration of radiolabelled $\left[{ }^{3} \mathrm{H}\right]$ curcumin was also studied by Ravindranath et al. in rat intestines at 50-750 $\mu \mathrm{g}$ in $10 \mathrm{ml}$ physiological medium, 30$80 \%$ of labeled curcumin was detected in the feces within $72 \mathrm{hrs}$ of ingestion [36]. Moreover, Pan et al. investigated the pharmacokinetic properties of native curcumin using a mouse model, a dosage of $100 \mathrm{mg} / \mathrm{kg}$ introduced via. intraperitoneal route and examined that after 1 hour of drug administration, maximum amount was found in the intestine $(117 \mu \mathrm{g} / \mathrm{g})$ while trace amounts were found in other organs like liver, spleen, kidney and brain of about 26.1, 26.9, 7.5 and $0.4 \mu \mathrm{g} / \mathrm{g}$ respectively. This observation has led to the lower absorption and poor bio-distribution of native curcumin [37].

Native curcumin also found to have a surprising potential in vitro but exhibits very low or no significant activity in vivo due to their poor lipid solubility of 0.6 $\mu \mathrm{g} / \mathrm{ml}$. The nonspecific distribution and inadequate accumulation upon intravenous administration which limits its efficacious response or therapeutic outcome [38]. To achieve the desired therapeutic effectiveness

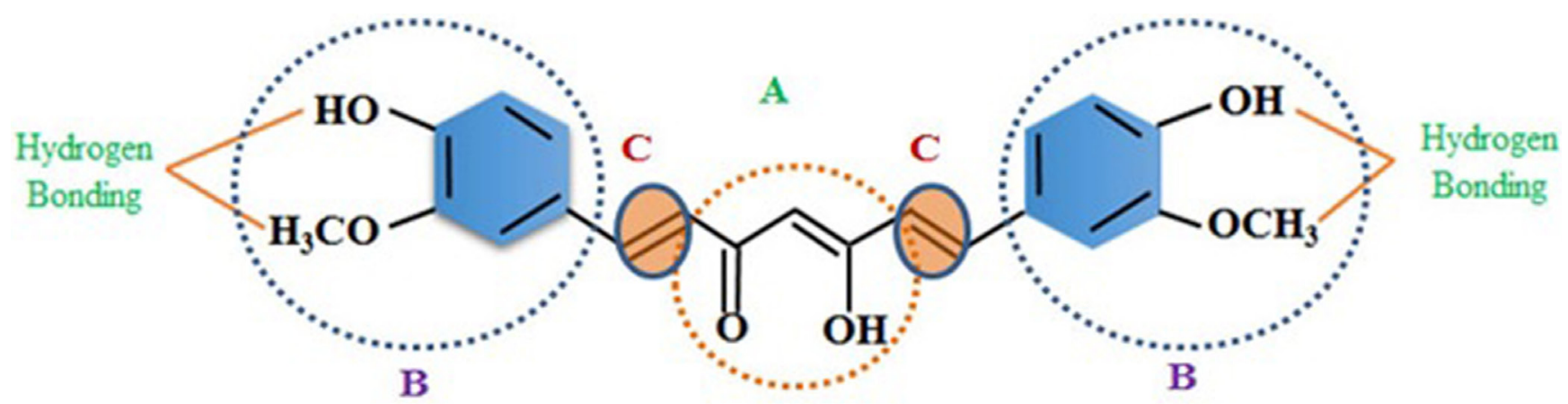

Figure 2: Structure of Curcumin (A) b-diketone or keto-enol; (B) phenolic; (C) alkene linker. Curcumin contains three chemical entities in its structure: two aromatic ring systems containing o-methoxy phenolic groups, connected by a seven carbon linker consisting of an $\alpha$, $\beta$-unsaturated $\beta$-diketone moiety. 
of this natural remedy, curcumin must deliver its active component to the specific site of injury at an optimal rate and amount. The amount of drug and dosage may vary from rapid and consummate absorption when an expeditious onset of action is required during acute conditions such as asthma, heart attack, to slow and sustained in case of longer circulation is needed depending upon their respective therapeutic objective. Thus, further research on curcumin is required to found some possible ways to overcome these limitations. By far, a number of biochemical advancements such as adjuvant merging with other dietary factors, hybridization with metals, liposomal curcumin, phospholipid complexes, conjugated with various polymeric materials and synthetic analogs have been proved to be a promising candidate to improve its bioavailability [39]. However, all of these studies reported the utilization of curcumin in their native form [40].

In addition to the substantial challenges presented individually, the important fact is still need to be noted that these all may vary in their complexity depending on different conditions, such as route of administration (oral vs. intravenous or intraperitoneal), type of disorder encountered (cancer vs. infection) and also the state of disease progression (early vs. late stage cancers) (Table 1).

Recently nano-therapeutics showed consequential amendment in therapeutic efficacy by designing and developing its nanoformulations (nanoparticles, nano gels, nanocrystals, liposomes etc.). The bioavailability and efficient delivery of curcumin can be made possible in the form of nano-curcumin which preserves the properties of curcumin and ascertains that it reaches the affected tissue [47]. It is also revealed that the nanoparticles with size ranging from 50-100 $\mathrm{nm}$ with marginal negative and positive surface charges are facilely internalized into cancer cells with high bio-interactions between cancer cells and drug particles due to their high contact surface area.

\section{Role of physicochemical properties of curcumin nanoparticles influencing its therapeutic efficacy}

\section{Particle size and its distribution}

Particle size plays a major role in the mode of action of drug including the interaction of particles with a biological system, tissue distribution, attachment, and rolling [48], firm adhesion of nanoparticles [49], phagocytosis [50], and accumulation [51] are all affected by the size of the particle. Due to the tailoring of a particle in a precise dimension for the purpose of getting the higher rate of absorption and permeation, it ultimately led to an incrementation in bio-distribution and longer circulation in vivo. The rate of excretion from the body is also high for large particles ( $>$ $1 \mu \mathrm{m})$, and gets aggregated under physiological conditions and not get filtered from capillaries [52]. In 2011, Liu et al. reported that the curcumin nanoemulsions inhibits $85 \%$ of TPA-induced mouse inflammation and also suppresses the expression of cyclin D. This nanoformulation of curcumin showed 3 fold increase in oral bioavailability [53].

Setthacheewakul et al. revealed the self-emulsifying liquid formulations of curcumin are more stable with a particle size of about $30 \mathrm{~nm}$ showed 10-14 folds higher rate of absorption compared to the same oral dose of native curcumin $(50 \mathrm{mg} / \mathrm{kg})$ administered in Wistar-strain rats [54].

\section{Surface properties of nanoparticles}

The most important characteristics of surface properties of nanoparticles are its surface area, charge present

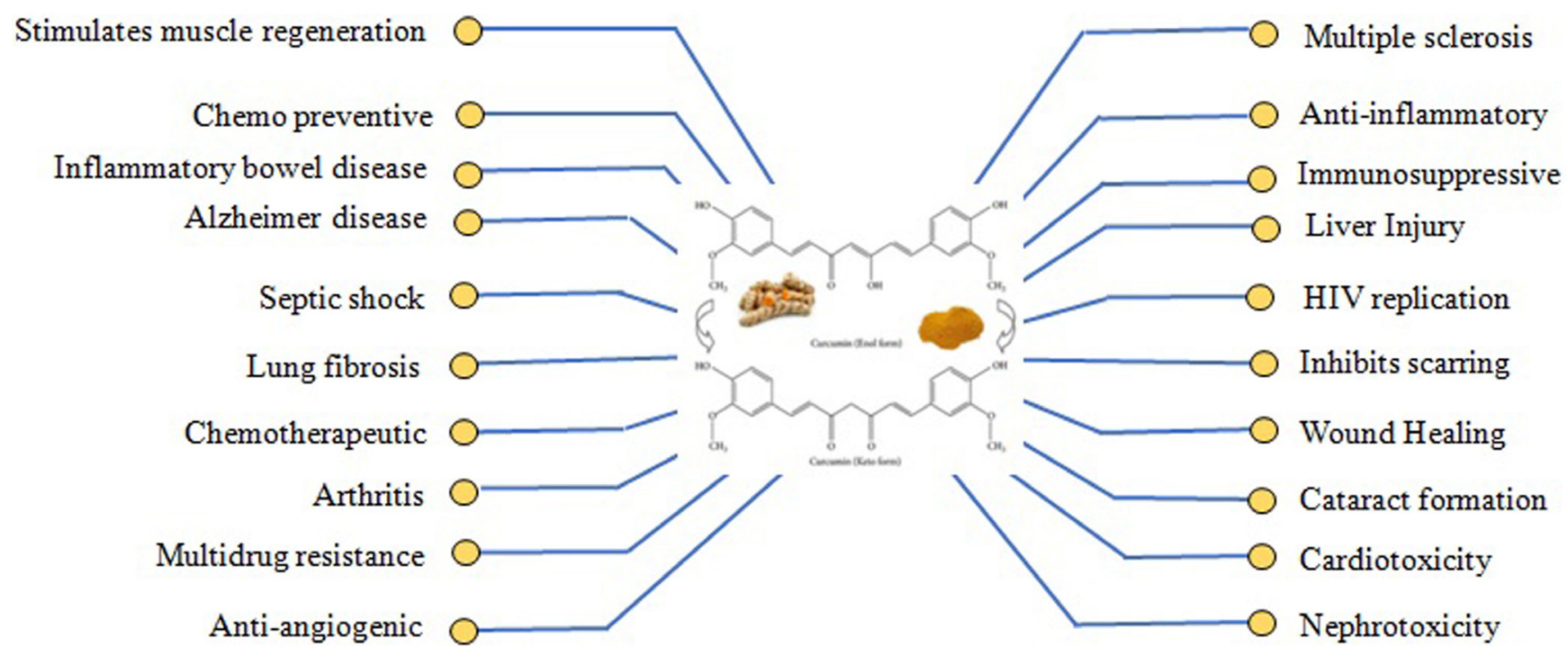

Figure 3: Therapeutic actions of curcumin. The Figure illustrates the different pharmacologic effects and therapeutic targets of curcumin. 
Table 1: Sundry clinical tribulations utilizing curcumin with expected outcomes

\begin{tabular}{|c|c|c|c|c|}
\hline Type of Cancer & $\begin{array}{c}\text { Effective drug concentration } \\
\text { in clinical trials }\end{array}$ & $\begin{array}{c}\text { Route of } \\
\text { administration }\end{array}$ & Outcome & References \\
\hline Cervical & $\begin{array}{c}500-12000 \mathrm{mg} / \mathrm{day} \\
\text { (11 patients) }\end{array}$ & Oral dose & $\begin{array}{l}\text { Curcumin found to be } \\
\text { safe and efficacious with } \\
\text { no adverse side effects }\end{array}$ & $\begin{array}{l}\text { Cheng et al., } \\
2001[41]\end{array}$ \\
\hline Colon & 4 g/day (44 patients) & Oral & $\begin{array}{l}\text { Significant reduction } \\
\text { in ACF number with } \\
\text { five-fold increase in } \\
\text { bioavailability }\end{array}$ & $\begin{array}{l}\text { Carroll et al., } \\
2004 \text { [42] }\end{array}$ \\
\hline Head and Neck & $\begin{array}{l}\text { Curcumin tablets } 1,000 \mathrm{mg} \\
\text { (34 patients) }\end{array}$ & Orally chewed & $\begin{array}{l}\text { Curcumin inhibited IKKß } \\
\text { kinase activity in saliva } \\
\text { of HNSCC patients with } \\
\text { reduced expression of no. } \\
\text { of cytokines }\end{array}$ & $\begin{array}{c}\text { Kim et al., } 2011 \\
{[43]}\end{array}$ \\
\hline Pancreatic & $\begin{array}{c}\text { Gemcitabine+Curcumin (8 gm) } \\
\text { (17 patients) }\end{array}$ & Oral & $\begin{array}{l}\text { Extremely safe and } \\
\text { feasible for pancreatic } \\
\text { cancer patients }\end{array}$ & $\begin{array}{l}\text { Epelbaum et al. } \\
2010[44]\end{array}$ \\
\hline Breast & $\begin{array}{c}\text { Curcumin }+ \text { docetaxel (6 gm/ } \\
\text { day) } \\
\text { (14 patients })\end{array}$ & Oral & $\begin{array}{c}\text { No adverse side effects } \\
\text { were obtained }\end{array}$ & $\begin{array}{l}\text { Bayet-Robert et } \\
\text { al., } 2010 \text { [45] }\end{array}$ \\
\hline $\begin{array}{l}\text { Chronic myeloid } \\
\text { leukemia }\end{array}$ & $\begin{array}{l}\text { Curcumin }+ \text { imatinib }(5 \mathrm{~g}) \\
\qquad(25 \text { patients })\end{array}$ & Oral & $\begin{array}{c}\text { Showed better efficacy } \\
\text { with decreased nitric } \\
\text { oxide levels }\end{array}$ & $\begin{array}{l}\text { Ghalaut et al., } \\
2012 \text { [46] }\end{array}$ \\
\hline
\end{tabular}

on it and its hydrophilicity. The nano formulation of any particle ranges from $1 \mathrm{~nm}$ to $1000 \mathrm{~nm}$, reduction in the size of the material results in an exponential increase in surface area to volume ratio. This may result in enhanced reactivity which dictates its extent of bio-distribution among the tissues and body organs with the rate of excretion from the body.

The surface charge of the nanoparticle is also a paramount feature represents the perpetuated circulation of the drug with enhancement in the accumulation rate at the site of interest. The negatively charged particles have reduced adsorption rate of serum proteins, resulting in longer circulation half-lives [55] as compared to the positively charged particles. The positively charged particles have a high non-specific rate of cellular uptake in the majority of cells.

\section{Shape of particle}

Particle shape is another essential property of nanoparticles that plays a pivotal role in various biological processes associated with its therapeutic activity [56]. The shape of nanoparticle affects its blood circulation, ability to transport, binding affinity, targeting, and internalization into the affected cells and tissues [57]. Geng et al. investigated that the shape of the particle also affects the circulation period of the drug, they observed the polymer micelles (filo micelles) of filamentous in shape have long-circulating lifetimes $(>1$ week after administration) compared with spherical counterparts
(2-3 days) [58]. The shape of nanoparticles contributes to their interaction with cell membranes. Recent studies have indicated that the oblate shape of particles favors their circulation in the blood due to lower uptake by macrophages [59]. Subsequently, it also increases their blood circulation period and targeted delivery to the site. The shape of nanoparticle also effected its bio distribution and macrophage uptake level. For a nanoparticle, to increase their circulation time and retention power in the cell, it must first be able to travel in the bloodstream while evading uptake by macrophages, particularly in the reticuloendothelial system. Biodistribution studies have also demonstrated that the uptake of spherical particles is favored over the uptake of particles with high aspect ratios in macrophages. The tailoring of nanoparticle shape and dimenison also has improved the efficacy of tumor therapy. For example, trastuzumab coated nanorods exhibited a 5-fold greater cellular growth inhibition of when BT-474 breast cancer cells compared to equivalent nanospheres at the same nanoparticle dose [60]. This leads to increase of upto $66 \%$ in binding ability and uptake by the cells of the nanorods compared to the nanospheres.

\section{Effect of aggregation and agglomeration on particle}

The aggregation and agglomeration of nanoparticles is seems to be a ubiquitous phenomenon which affects in mediating cellular uptake and interactions. The formation 
of large NP complexes in suspension is frequently referred to as 'aggregation' or 'agglomeration'. It occurs due to the effect of van der Waals attractive forces between particles are greater than the electrostatic repulsive forces produced by the nanostructure surface $[61,62]$. They both effects dramatically with many aspects of nanoparticlecell interactions. Particle agglomeration is influenced by a number of factors, including primary particle characteristics as well as the properties of the medium that the particles are suspended in [63]. The aggregation states of nanoparticles also influence their toxicities. Fundamentally, the aggregation states of nanoparticles depends on size, surface charge, and composition among others. It has been observed that carbon nanotubes are mainly accumulated in liver, spleen, and lungs without manifesting any acute toxicity but induce cytotoxic effects mostly because of accumulation of aggregates for longer periods [64]. Agglomerated carbon nanotubes have more unpropitious effects than well-dispersed carbon nanotubes and enhance the pulmonary interstitial fibrosis [65].

\section{Encapsulation efficiency of particle}

The rational design strategy of encapsulation efficiency or surface coating of nanoparticle greatly influences its solubility and interaction with the other biological entities. It also affects their chemical reactivity and pharmacokinetic property of nanoparticle [66]. The nanoparticle encapsulation efficiently overcomes many of its impediments like targeted drug delivery approach, cellular uptake, biodistribution and accumulation at the site of interest.

Many researchers used polymeric materials like Poly (lactic-co-glycolic) acid (PLGA), Polyethylene glycol (PEG), surfactant copolymers for encapsulating the nanoparticles with the purpose of maintaining the higher stability of the nanoparticulate system in biological milieu [67]. Recently, the neuronal uptake and neuroprotective effects of curcumin loaded PLGA nanoparticles in the human SK-N-SH cell line have been observed [68]. It has also been shown that curcumin encapsulated in PLGA nanoparticles may induce neurogenesis and reverse cognitive deficits in Alzheimer's disease model [69]. Moreover, many polymeric nanoparticles composed of $\mathrm{N}$-isopropylacrylamide (NIPAAM), vinylpyrrolidone (VP), and acrylic acid (AA) containing curcumin (NanoCurc ${ }^{\mathrm{TM}}$ ) protected human SK$\mathrm{N}-\mathrm{SH}$ cells from ROS hydrogen peroxide $\left(\mathrm{H}_{2} \mathrm{O}_{2}\right)$-mediated cell damage $[70,71]$ Mulik et al showed that apolipoprotein E3 (ApoE3) mediated PnBCA nanoparticles containing CUR exhibit neuroprotective action against $\mathrm{A} \beta$-induced cytotoxicity in SH-SY5Y cells $[72,73]$.

\section{Drug content and release profile of nanoparticle system}

The content of drug loaded and its release profile at the site of interest of any nanoparticulate system is highly dependent on the type of nanoparticle used and its method of preparation. In the case of curcumin nanoparticles, the amount of drug encapsulated has been quantified using different estimation methods [74-76].

Zhu et al. studied the drug release profile of curcumin encapsulated with poly (butyl cyanoacrylate) nanoparticles and observed $34.7 \%$ release in 2 hours followed by a sustained release using standard twophase kinetics equation: $100-\mathrm{Q}=4.5235 \mathrm{e}(-0.1724 \mathrm{t})+$ $4.1641 \mathrm{e}(-0.0114 \mathrm{t})$ [77]. In most of the nanoformulations of curcumin, the in vitro release kinetic follows a biphasic pattern. The sustained release profile of curcumin nanoparticles may vary depending on different factors such as nano formulation, its composition, the location of entrapment and amount. The rational tailoring of nanoparticle design and prepared in such a way with an intrinsical capacity of high drug entrapment efficiency and loading capacity. The drug loaded and release is an important factor as the therapeutic potential of curcumin nanoformulation is greatly dependent on its release in its active form at the targeted site of interest.

\section{Nanotechnological interventions of native curcumin to overcome its inherent constraints}

The emergence of nanotechnology has now caused the convergence of experimental advancements for the welfare of society with a wide range of applications and use of nano-scale phenomena with novel properties for a felicitous remedial action. Nanotechnology has proved to be a very efficacious implement for various strategies accentuated ecumenically to escalate the constraints of native curcumin for the enhancement of its therapeutic potential coupled with some important factors, including high cellular uptake, biodistribution, dissolution rates, good blood stability and controlled drug release at the site of injury.

The different types of nano-carriers were utilized for curcumin nanoparticle formulation such as polymeric nanoparticles, solid-lipid nanoparticles, polymeric micelles, curcumin nanocrystals, nano-emulsions, nano liposome-encapsulated curcumin, Cyclodextrin, curcumin nanosuspension and dendrimers. They provide protracted blood circulation, better permeability, and resistance to metabolic processes [78] [Figure 4]. A number of studies were carried out to elucidate the different nano formulations of curcumin for effective therapeutic activity (Table 2).

Recently, Sasaki et al. reported curcumin encapsulated into methoxy poly (ethylene glycol) poly (E-caprolactone) nanoparticles with effective drug delivery and enhanced oral bioavailability [87]. The encapsulation of curcumin with more than $97.5 \%$ potency in PLGA and PEG was studied by Garodia et al. and proved that the encapsulation shows higher efficacy and faster cellular uptake than the native curcumin in vitro [88]. 
Table 2: Nano-technological alteration in herbal drug curcumin along with their expected benefits

\begin{tabular}{|c|c|c|c|c|}
\hline $\begin{array}{c}\text { Nanotechnology } \\
\text { tool }\end{array}$ & Size and shape & Models used & Outcome & References \\
\hline $\begin{array}{l}\text { Curcumin } \\
\text { encapsulated with } \\
\text { liposomal PMSA } \\
\text { antibodies }\end{array}$ & $100-150 \mathrm{~nm}$ & $\begin{array}{c}\text { Human Prostate cancer } \\
\text { cell lines (LNCaP and } \\
\text { C4-2B }\end{array}$ & $\begin{array}{l}\text { Showed better } \\
\text { efficacy( } 70-80 \% \\
\text { inhibition in cell } \\
\text { proliferation) with } \\
\text { enhanced targeted } \\
\text { delivery }\end{array}$ & $\begin{array}{c}\text { Thangapazham et al., } \\
2008 \text { [79] }\end{array}$ \\
\hline $\begin{array}{l}\text { Curcumin/MPEG- } \\
\text { PCL micelles }\end{array}$ & $27.3 \pm 1.3 \mathrm{~nm}$ & $\begin{array}{l}\text { Colon carcinoma cell } \\
\text { (C-26) }\end{array}$ & $\begin{array}{l}\text { Excellent inhibition } \\
\text { of cancer growth by } \\
\text { inhibiting angiogensis }\end{array}$ & Gou et al., 2010 [80] \\
\hline $\begin{array}{l}\text { Curcumin loaded } \\
\text { PBCN nanoparticles }\end{array}$ & $152.0 \mathrm{~nm}$ & Alzheimer's disease & $\begin{array}{l}\text { Showed excellent } \\
\text { transport of curcumin } \\
\text { to brain }\end{array}$ & Sun et al., 2010 [81] \\
\hline $\begin{array}{l}\text { Curcumin } \\
\text { nanoemulsion }\end{array}$ & $<200 \mathrm{~nm}$ & $\begin{array}{l}\text { human ovarian } \\
\text { adenocarcinoma cells } \\
(\mathrm{SKV} 3) \text { and drug } \\
\text { resistant (SKOV-3TR ) }\end{array}$ & $\begin{array}{l}\text { Showed significantly } \\
\text { increased cytotoxic } \\
\text { activity }\end{array}$ & Ganta et al., 2009 [82] \\
\hline $\begin{array}{l}\text { Curcumin-PLGA } \\
\text { nanoparticles }\end{array}$ & $248 \pm 1.6 \mathrm{~nm}$ & $\begin{array}{l}\text { Erythroleukemia type } \\
\text { K562 cells }\end{array}$ & $\begin{array}{l}\text { Improved clinical } \\
\text { management of } \\
\text { leukemia }\end{array}$ & Misra et al., 2011 [83] \\
\hline $\begin{array}{l}\text { Curcumin-Chitosan } \\
\text { nanopartilces }\end{array}$ & $100-250 \mathrm{~nm}$ & Melanoma tumors & $\begin{array}{l}\text { Increased antitumor } \\
\text { and anti-cancer } \\
\text { effects }\end{array}$ & Li et al., 2012 [84] \\
\hline $\begin{array}{l}\text { Nanogels (cross } \\
\text { linked polymer } \\
\text { network) }\end{array}$ & $10-200 \mathrm{~nm}$ & $\begin{array}{l}\text { Breast and pancreatic } \\
\text { cancer cells }\end{array}$ & $\begin{array}{l}\text { Increased stability } \\
\text { with enhanced } \\
\text { anticancer effects }\end{array}$ & $\begin{array}{c}\text { Mangalathillam et al.2012 } \\
{[85]}\end{array}$ \\
\hline $\begin{array}{l}\text { Curcumin- } \\
\text { nanocrystal solid- } \\
\text { dispersion }\end{array}$ & $250 \mathrm{~nm}$ & $\begin{array}{l}\text { Pharmacokinetic } \\
\text { properties }\end{array}$ & $\begin{array}{l}\text { Improved } \\
\text { physiochemical } \\
\text { andpharmacokinetic } \\
\text { properties. }\end{array}$ & Onoue et al., 2010 [86] \\
\hline
\end{tabular}

Jourghanian et al. synthesized curcumin loaded solid-lipid nanoparticles by high-pressure homogenization method using mannitol as cryoprotectant and cholesterol as a carrier which enhances its stability and biocompatibility [89]. Another study demonstrated a novel folate-conjugated, curcumin-loaded human serum albumin nanoparticles (F-CM-HSANPs) prepared by the chemical conjugation of folate to the surface of curcumin loaded human serum albumin nanoparticles injected in vitro results in sustained drug release at desired site and prolonged retention time with specific targeting in vivo after the intravenous injection of F-CM-HSANPs in current clinical tribulations [90].

The cyclodextrin-based nanosponges of curcumin cross-linking with dimethyl carbonate were synthesized and formulated the intricate of $\beta$-cyclodextrin-curcumin nanosponge by Darandale et al. which significantly enhanced the stability as well as solubility compared to free curcumin. Also, the in vitro drug release efficacy of curcumin was found to be highly controlled over a prolonged duration and found to be non-hemolytic [91].
Sun et al., developed a cationic liposome containing PEI-PEG as a carrier involute (LPPC) encapsulate curcumin with enhanced anti-tumor effects on colon/ melanoma tumor growth in mice. It was found that curcumin/LPPC intricate exhibits enhanced the antiproliferative effect and is able to rapidly perforate into the cells [81].

In another study conducted by Mangalathillam et al., reported curcumin loaded chitin nano gels comprised of cross-linked polymer network tested in vitro on breast cancer cell lines and observed an amelioration in bioavailability, anticancer effects, better-controlled release and enhanced stability [85].

Kundu et al. reported curcumin-loaded lipid nanoparticles and investigated anti-glioma activity in encephalon tissue for effective glioblastoma therapy resulting in enhanced bioavailability. They demonstrated that curcumin-loaded nanoparticles inhibited cellular proliferation, migration, and incursion along with a higher percentage of cell cycle arrest and telomerase inhibition, thus leading to a more preponderant percentage of 
apoptotic cell death in glioma cells compared with native curcumin. Thus, curcumin-loaded nanoparticles can be utilized as an effective delivery system to surmount the challenges of drug delivery to the brain, providing an incipient approach to glioblastoma therapy [92]. These novel strategies significantly ameliorated curcumin's aqueous solubility, cellular uptake, controlled release with enhanced dissolution rates.

Recently, researchers from Johns Hopkins University School of Medicine and the University of Delhi have jointly developed a polymer nanoparticleencapsulated form of curcumin, "nano-curcumin", which can be readily dispersed in aqueous media. In this process, they have coated ordinary hydrophobic curcumin particles with a hydrophilic polymer (N-isopropyl acrylamide) with N-vinyl-2-pyrrolidonne and poly (ethylene glycol) monoacrylate nanoparticles. This nano formulation increases aqueous solubility and can be readily absorbed into the blood stream. It has already been tested in vitro on pancreatic cancer cells and it was shown to have equal or better effects than free curcumin on the human cancer cells, such as inhibition of
NF-kB and down-regulation of interleukin-6 (IL-6) [93]. The comparative study of various nanotechnological strategies used for the preparation of nanoformulation of native curcumin using different encapsulation methods and the novel approach of converting native curcumin absolutely in a nano range without any encapsulation are illustrated in Figure 5.

\section{How curcumin nanoformulations affects its pharmacological behavior?}

Nanoformulations of curcumin greatly transmuted the way of treating diseases by amending its bio-availability, cellular uptake, and permeability with enhanced plasma concentration. Curcumin nanoparticles efficaciously distribute the exact therapeutic concentration of drug at the site of injury. Numerous studies have been reported on the therapeutic efficacy of curcumin nanoformulations and explored its consequential properties against the wide range of human diseases [94]. The pharmacophore elements in curcumin such as central 5-hydroxy-1, 7-diarylhepta-1, 4, 6-trien-3-one and 3-methoxy-4-hydroxyl aryl rings

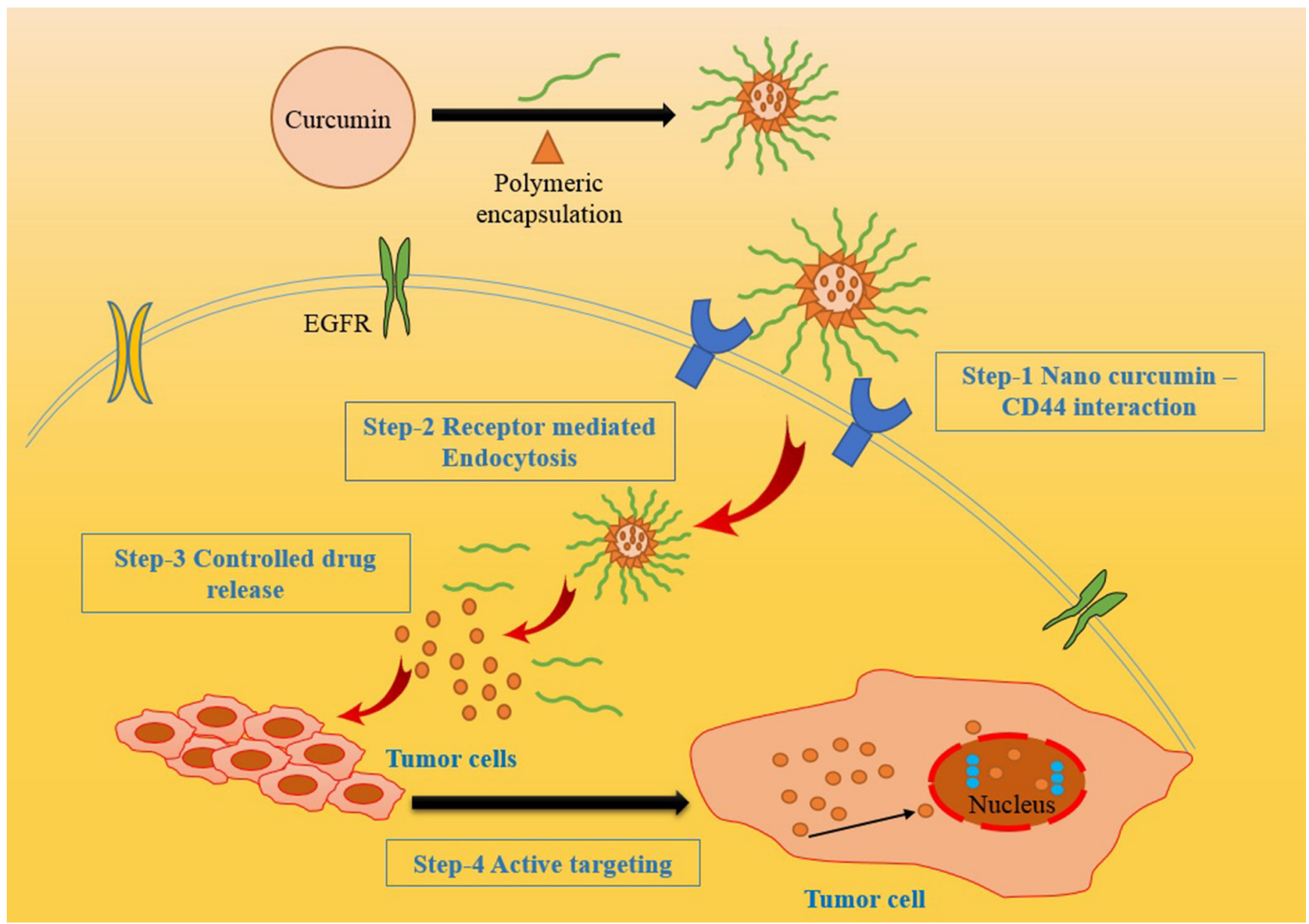

Figure 4: Different nano carriers of curcumin for enhanced drug delivery system. The various nano-carriers with effective encapsulation strategies to enhance the targeted drug delivery. 
and $\alpha, \beta$ unsaturated carbonyl, confer a large variety of biological activities, involved in cellular defense against oxidative stress and chemo-preventive effect [95] and its detailed mechanism of action has been illustrated in Figure 6. Recent research and numerous studies on animals have also focused on the adequacy and safety in the utilization of curcumin nanomedicine on several types of biological activities. [96].

\section{Anti-inflammatory activity of curcumin nanoformulations}

The nano formulations of curcumin have potentially amended the major obstacles of native curcumin such as low solubility, instability, poor bioavailability and rapid metabolism. Consequently, curcumin nanoparticles gained immense attention to improve its profound activity against diverse inflammatory conditions such as bronchial asthma, uveitis, periodontitis, inflammatory bowel diseases etc [97]. In 2015, Abdul Mohsen et al. prepared amorphous nanocurcumin using water titration method and evaluated its antiinflammatory effects in vitro and ex vivo in carrageenaninduced paw edema method in rats with Diclofenac as standard and concluded that NanoCur was highly significant and efficacious as compared to native curcumin [98].
The anti-inflammatory activity of curcumin complexes is reported due to the presence of 4-hydroxyphenyl unit which is further increased by the integration of acylation and alkylation or methoxy groups on the phenyl ring of curcumin [99]. As an antiinflammatory, curcumin causes downregulation of NF$\mathrm{kB}$, cyclooxygenase 2 (COX2) and pro-inflammatory cytokines such as interleukin-1 (IL-1 and IL-6) and TNF- $\alpha$ and showed high efficacy against rheumatoid arthritis, psoriasis, and post-operative inflammation [100]. Curcuminoid showed marked improvement in patients and was also found to be safe and highly efficacious throughout the clinical trial $[101,102]$.

Oppenheimer et al, conducted the first clinical tribulation of native curcumin in human biliary diseases to investigate the effect of "curcumen" by intravenous injection of $5 \%$ sodium curcumin solution which showed rapid vacating of the gallbladder and patient showed consummate remedy [103].

Another study was conducted among 16 patients suffering from chronic kidney disease to evaluate the antiinflammatory effect of a curcuminoid and found to be mediated by regulating the inflammatory mediators such as IL-6, IL-8, TNF- $\alpha$, TNF- $\beta$, substance P, hs-CRP, CGRP, and MCP-1. Curcuminoid showed marked amelioration in

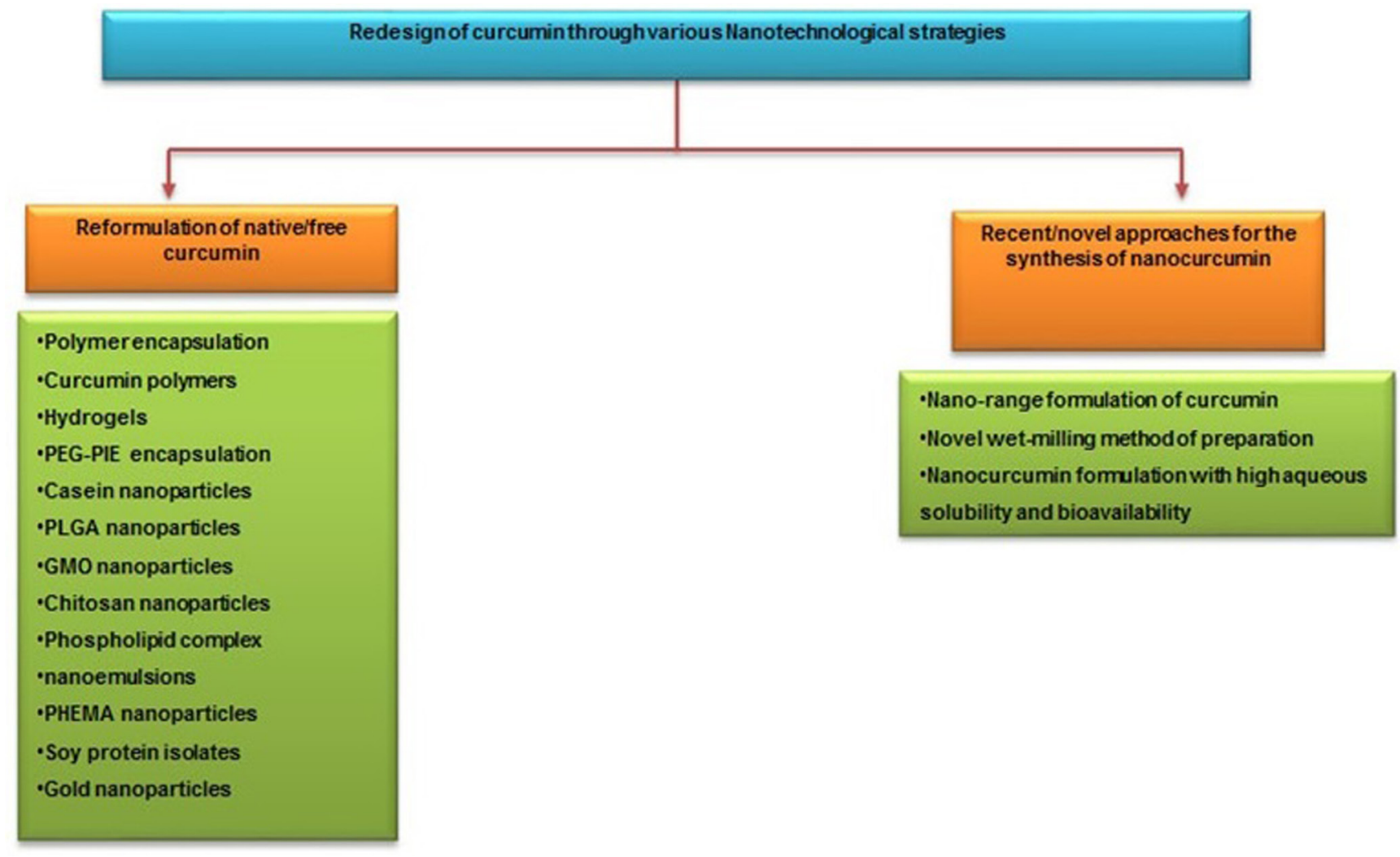

Figure 5: Comparative study of different strategies used for the preparation of nano curcumin for amended drug uptake and bio distribution. 
patients and was additionally found to be safe and highly efficacious throughout the clinical trial [104]. Another study on rat intestine showed that curcumin enhanced the expression of SOCS-1, via down-regulation of JAK2/ STAT3 signaling [105]. The anti-inflammatory effect of Cyclodextrin-mediated curcumin complex was evaluated and found that Cyclodextrin-curcumin intricate showed higher affinity than native curcumin in inhibiting the inflammatory transcription factor, such as nuclear factor kappa-b $(\mathrm{NF}-\kappa \mathrm{B})$ and also tested for the treatment of inflammatory bowel disease in rat model. [106, 107].

\section{Anti-oxidant activity of nano-curcumin}

The structure of curcumin contains a carbonyl, methoxy and hydroxyl groups pertaining to its antioxidant activity due to its ability to scavenge free radicals in vivo, especially peroxyl radicals (ROO). Albeit curcumin contains a $\beta$-diketone moiety which may subsist in a cis, Trans and enol form. Tonnesen et al reported that curcumin subsits in the cis-enol form in solutions [108].

Vajragupta et al. demonstrated inhibition of oxidative stress by curcumin in humans during exercise and also found decremented astringency of pre-menstrual syndrome in women by regulating the neurotransmitters and biomolecule levels. The defensive properties of curcumin are attributed a symmetrical di phenolic dienone series which includes members that retained or were devoid of phenolic groups [109].

Studies revealed that expression of 2 and 4- hydroxyphenyl units and an ortho alkoxy group contributed to the enhancement of antioxidant activity $[110,111]$. However, under the situations of extortionate engenderment of peroxynitrite and hydrogen peroxide oxidants, curcumin react with peroxyl radicals and composed phenoxyl radicals which show less reactivity than the peroxyl radicals. Further, it was reported that polyethylene glycosylated (PEGylated) curcumin analogs

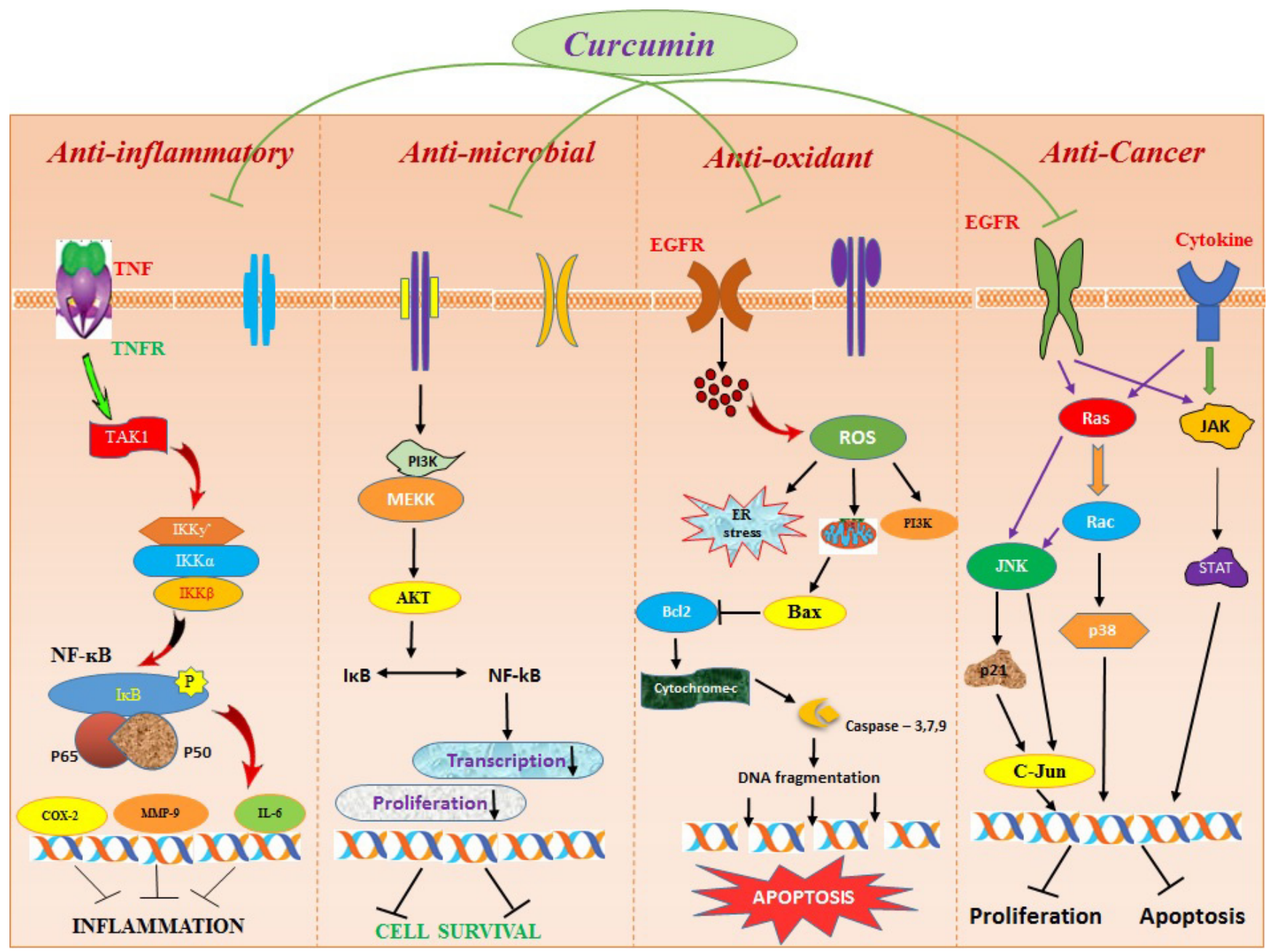

Figure 6: Mechanism of action of curcumin in different biomedical applications. The Figure illustrates the detailed mode of action of curcumin mediated for different therapeutic applications by entering inside the cell through appropriate cell surface receptors with efficacious targeted distribution and enhanced response by regulating various cytokines and induces apoptosis in cancer cells. 
for potent nuclear factor erythroid-2 cognate factor 2 (Nrf2) activators that regulate the antioxidant defense system and act as modifiers for inflammatory diseases [112]. Few studies have revealed up-regulation of endogenous cellular antioxidant contrivances following curcumin administration that contributed the initiation of cytoprotective Nrf2-induced target genes which scavenged reactive oxygen species (ROS) thereby protecting cells from ROS-induced oxidative stress [113-115].

In recent years an incipient biopolymer micelle of curcumin has been prepared by encapsulating with modified $\mathcal{E}$-polylysine (M-EPL) micelle and demonstrated that M-EPL encapsulation effectively stabilized curcuminoid showed elevated cellular antioxidant activity compared with native curcumin [116].

\section{Anti-microbial activity of nano-formulated curcumin}

The development of resistance against subsisting microbial drugs has become a critical quandary for therapeutic strategies. Due to the antimicrobial activities of native curcumin, the research has been expedited to get insight into the aspect of controlling pathogens. This polyphenol compound has shown a wide range of activity against various microorganisms such as Bacillus subtilis, Staphylococcus aureus, Pseudomonas aeruginosa, Escherichia coli, Aspergillus niger, Penicillium notatum, Salmonella paratyphi, Mycobacterium tuberculosis and certain pathogenic fungi $[117,118]$.

Nanoformulation of curcumin possesses enhanced antibacterial potential activity than native curcumin which is attributed to its improved aqueous-phase solubility and dispersing ability. Curcumin induced membrane permeabilization is involved in disordering the 1, 2-dipalmitoyl-sn-glycero-3-phosphocholine (DPPC) membranes [119].

Curcumin inhibits the FtsZ polymerization thereby suppress the FtsZ assembly possibly leading to disruption of E. coli and B. subtilis proliferation [120]. In 2015, Gera et al. fabricated a nano-curcumin loaded medicated patch with controlled drug release efficacy and revealed that the nano-curcumin coated bandage showed enhanced bioactivity against different pathogenic and nonpathogenic microbial strains [121]. The encapsulation of curcumin with chitosan-PVA-silver nanocomposite films has been studied by Vimala et al. as an anti-microbial wound/burn dressings and identified enormous growth inhibition of $E$. coli in comparison with native curcumin or chitosan-PVA-silver nanoparticles film discretely [122].

Curcumin also showed significant therapeutic potential against Helicobacter pylori. An explanatory study in Helicobacter pylori-infected C57BL/6 mice utilizing curcumin exhibited eradication effect against the infection and restored gastric damage [14]. The anti-fungal activity of curcumin against pathogens derived from food such as Penicillium notatum, Aspergillus niger and Saccharomyces cerevisiae has shown the prominent possibility for the utilization in the pabulum industry [123]. The potential mechanism of antifungal activity of curcumin is due to the breach in the integrity of plasma membrane which caused leakage of potassium ion from the cytosol and transmute in membrane potential leading to cell death. The study also suggested that downregulation of desaturase (such as ERG3) leading to significant reduction in ergosterol of fungal cell lead to cell death via generation of ROS [124].

The antiviral activity of curcumin has been reported against numerous viruses, including influenza virus infection (IAV), human papilloma virus (HPV), coxsackievirus, Hepatitis $\mathrm{C}$ virus (HCV), adenovirus and Herpes simplex 1 (HSV-1). It is well documented that curcumin is a strong inhibitor of NF-kB signaling that might impact upon IAV propagation [125]. In vitro study using curcumin and its derivatives exhibited remarkable antiviral activity against herpes simplex virus type 1 (HSV1) [126]. The coalescence of curcumin and IFN $\alpha$ inhibited the HCV viral replication through the Akt-SREBP-1 activation thereby inhibiting HCV gene expression [38]. Undeniably, adscititious studies are still needed to attest the usefulness of curcumin in the treatment of patients with highly prevalent viral infections. Apart from some reports on the therapeutic efficacies of curcumin, research areas nowadays are majorly focused on the utilization of nano-curcumin for its immune-modulatory and antimicrobial effects against HIV and other pernicious microbes such as influenza virus, adenovirus, cox sackie virus and Mycobacterium tuberculosis.

\section{Anti-cancer activity of nanoformulation mediated curcumin}

The influx of nanotechnology brings an abundance of opportunities for elongating the therapeutic activities of this natural remedy, curcumin by improving its aqueous dispersion, bioavailability and cellular uptake. Curcumin is a highly pleiotropic molecule which shows positive efficacy as a chemopreventive agent against the malignant tumor proliferation in colon, breast, prostate, esophagus and lung etc.

Curcumin has attracted great attention in the therapeutic activity in clinical oncology due to its chemo preventive, antitumor, radio sensibilizing and chemosensibilizing activities against various types of cancer cells. These malignancies include breast, ovarian, prostate, leukemia's, lymphomas, multiple myeloma, brain cancer, melanoma and skin and lung cancers. Curcumin mediates its anti-proliferative, anti-invasive and apoptotic effects on cancer cells through multiple molecular mechanisms. The oncogenic pathways inhibited by curcumin encompass the members of epidermal growth factor receptors (EGFR), sonic hedgehog (SHH)/GLIs 
and $\mathrm{Wnt} / \beta$-catenin and downstream signaling elements such as Akt, nuclear factor-kappa B (NF- $\mathrm{B})$ and signal transducers and activators of transcription (STATs) (Figure 7) [127]. In counterbalance, the high metabolic instability and poor systemic bioavailability of curcumin limit its therapeutic efficacy in human. Of great therapeutic interest, the selective delivery of synthetic analogs or nanotechnology-based formulations of curcumin to tumors, alone or in combination with other anticancer drugs, may improve their chemo preventive efficacies against cancer progression. Novel curcumin formulations may also be used to inhibit the drug resistance, eradicate the total cancer cell mass and improve the anticarcinogenic efficacy in patients.

Studies have indicated the therapeutic efficacy of curcumin has been considered as safe and potent drug and exhibits no major toxicity and only protects normal cells and organs at least in part by up-regulating the nuclear factor erythroid-derived-2 related factor 2 (Nrf2)-induced antioxidant gene products. In the studies of Zaman et al., 2016 prepared poly (lactic-co-glycolic acid) predicated curcumin nanoparticle formulation and demonstrates that the polymeric nanoparticle efficaciously inhibits the cell growth, induces apoptosis and cell cycle arrest in cervical cancer cell lines as compared to the native curcumin. [128].

Mukherjee and Vishwanatha et al., prepared the nanospheres of curcumin with encapsulation of PLGA and evaluated against prostate cancer cell lines, LNCaP, PC3, and DU145 revealed that the $\mathrm{IC}_{50}$ value of cells treated with polymer encapsulated nano-curcumin is less than the native or free curcumin treated cells [129]. Various polymeric nano formulations of curcumin were synthesized by crosslinking of $\mathrm{N}$-isopropyl acrylamide,

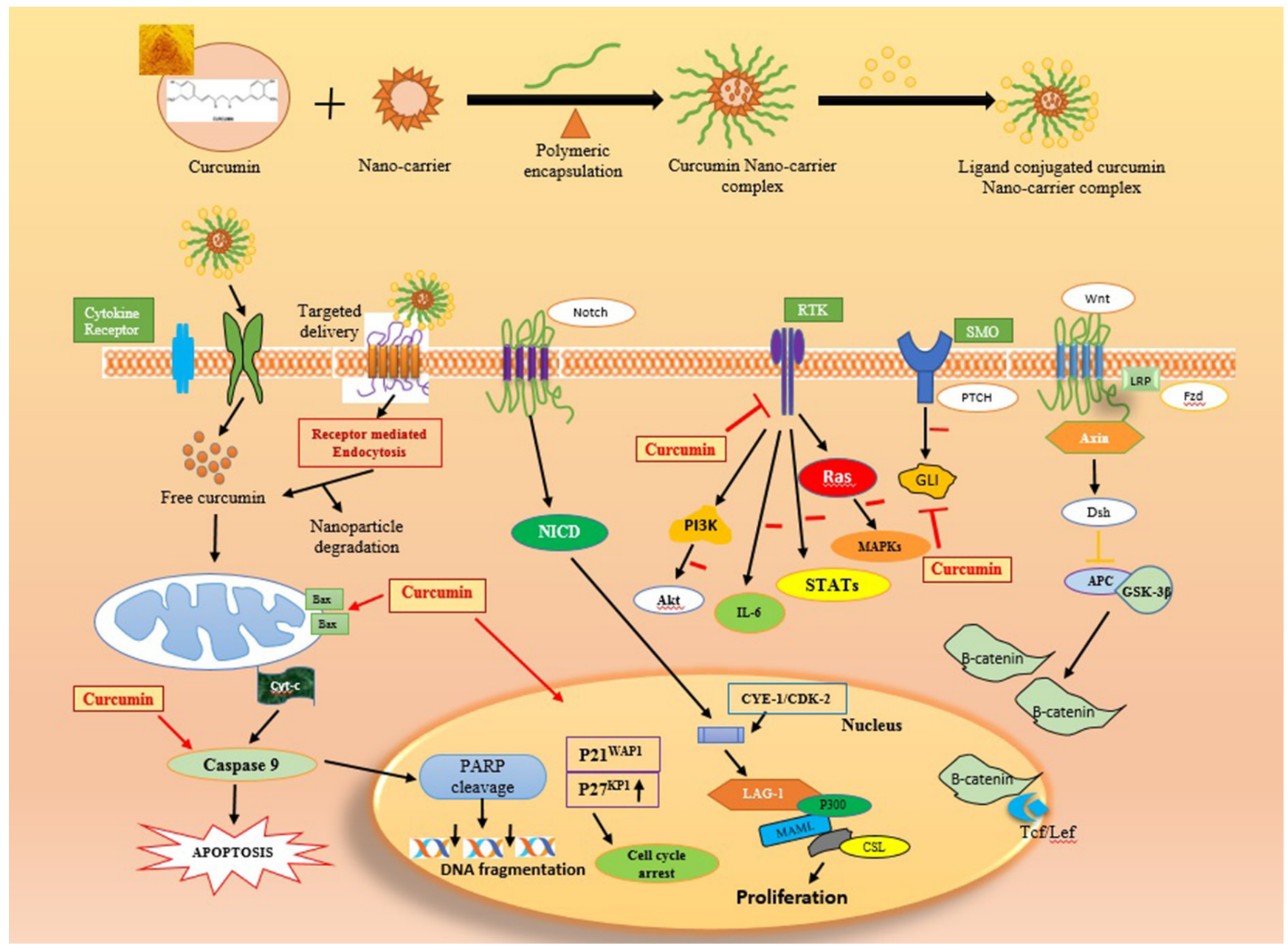

Figure 7: Multiple anti-cancer cascades of curcumin by different growth factors in cancer cells. The inhibitory effect of curcumin on the expression and/or activity of EGFR, erbB2, IGF-1R, and their downstream signaling elements, sonic hedgehog (SHH/ $\mathrm{SMO} / \mathrm{GLIs}), \mathrm{Wnt} / \beta$-catenin and ATP-binding cassette multidrug transporters such as ABCG2 in cancer cells are indicated. Moreover, the enhanced expression of $\mathrm{p} 21^{\mathrm{WAP} 1}$ and $\mathrm{p} 27^{\mathrm{KIP} 1}$ Cyclin-dependent kinase inhibitors and inhibition of mitotic effects induced by curcumin resulting in a cell cycle arrest and reduced expression levels of different gene products involved in the growth, invasion and metastasis of cancer cells as well as the activation by curcumin of mitochondrial factors and caspase pathway-induced apoptosis are also indicated. 
$\mathrm{N}$-vinyl-2-pyrrolidone, and poly (ethylene glycol) monoacrylate and studied its anti-proliferative activity against pancreatic cancer cells and amended results were obtained in the case of polymer loaded nanoparticles as compared to native curcumin [93].

The anticancer activity was also studied against breast cancer cell lines by induction of apoptosis using Transferrin-mediated solid lipid nanoparticles (SLNs) of curcumin and the flow cytometric results concluded that the transferrin-mediated SLNs nano-curcumin has potentially gives enhanced anticancer activity of curcumin in breast cancer cell lines in vitro compared to the native or free curcumin [130].

Extensive studies, both in cancer cell lines and animal tumor models have reported the higher cellular uptake in nano-formulated curcumin in cancer cells than native curcumin by inhibition of chemokine and metastasis, thereby delaying or inhibiting the proliferation $[131,132]$. The multiple mechanisms involved in cell proliferation (Cyclin D1, c-Myc), cell survival (Bcl-2, Bcl-xL), and apoptosis (caspase -8, 3, and 9) may mediate the permissive chemotherapy and chemopreventive effects for a selective targeting of highly proliferating cancer cells over normal cells $[133,134]$. At the molecular level, the anticancer effects of curcumin are underlying the mechanism of action through inhibiting the expression of the specificity protein ( $\mathrm{Sp}$ ) transcription factors $\mathrm{Sp} 1, \mathrm{Sp}$, and Sp4 [135, 136].

The suppression of malignant tumor progression utilizing curcumin revealed the diverse and complex mechanism of action by up-regulation of pro-apoptotic proteins such as Bim, Puma, Bax, Bak, Noxa; downregulation of anti-apoptotic proteins such as XIAP, $\mathrm{Bcl}-2$, and Bcl-xL; growth factor receptors (such as EGFR, HER2) and inhibits the activity of c-Jun N terminal kinase [137], protein tyrosine kinases and protein serine/ threonine kinases which reduced the metastatic activity [138].

Curcumin has many molecular targets and has a diverse and complex mechanism of action. Curcumin regulates the transcription factors of NF-kB resulting in Upregulation of the expression of anti-apoptotic genes expression that is implicated to be involved in carcinogenesis [139]. The curcuminoid showed a reduction in cancer cell proliferation by suppressing the cell cycle regulatory proteins Cyclin E, Cyclin D1 Cyclin B [140]. The MMPs family member proteins are reported to play a vital role in malignant tumor progression and metastasis [141]. In vivo study showed that curcumin inhibits the expression of MMP-2 and MMP-9 in B16F10 melanoma cells [142].

From last few decades, the investigations have explored the curative effects of curcumin in endometrial and ovarian cancer cells on the negative controllers of activated STAT-3 like SHP-1, SHP-2, SOCS and PIAS $[143,144]$. The coalescence effect of curcumin and docetaxel treatment against multidrug resistant tumors in mice ovarian has shown significant reduction about $58 \%$ in growth of the tumor. The report demonstrated that administration of curcumin $(500 \mathrm{mg} / \mathrm{kg} /$ day $)$ leads to increment in apoptotic activity of tumor cells, reductions in the growth of tumor up to $49-55 \%$ and microvessel density of normal ovarian tumor cells [145].

The tgf- $\beta$ signaling pathway is a tumor inhibitor, but alterations in TGF- $\beta$ signaling pathway promotes cancer. The cytotoxic effect of curcumin on colon and cervical cancer cell lines via inhibiting the TGF- $\beta$ signaling cascade [146]. It is downregulated TGF- $\beta$ signaling pathway such as $\mathrm{p} 21$, cyclinD1, and Pin1 by lowering the expression of Smad4, P-Smad3, and TGF- $\beta$ Receptor II. The study in mouse xenograft model showed the chemopreventive effect of curcumin on colorectal cancer cell lines regulates the tumor-suppressive miR-34a, specific miRNAs, and down expression of miR-27a.

Apart from some reports on the therapeutic efficacies of nano-curcumin for the treatment of parasitic diseases, microbial diseases and toxicity, most research areas are majorly focused on the utilization of nanoformulated curcumin for cancer therapy, showed improved targeted anticancer effect compared to native curcumin [147]. In a polar medium, curcumin has the unique ability to perforate into the cell and with an excellent electron transfer capability can facilely enter into the plasma membrane of the cell. Hence, the particle size of curcumin nanoparticles demonstrated better aqueous phase solubility and having much more vigorous anticancer effect against various cancer cell lines [148]. Consequently, nano formulations of curcumin showed ameliorated therapeutic efficacy compared to bulk or native curcumin.

\section{CONCLUSIONS}

Nanotechnology is not only the stream of infinite possibilities but a burgeoning field for prospective future, but it is realistic to many scientists and investigators working to accomplish incredible goals every day. The current review article accentuates on a native medicinal herb "Turmeric" and its active ingredient, "Curcumin" as a unique therapeutic agent. Despite its incredible multitargeting potential in vitro, its pharmacological efficacy is obstructed in vivo due to some major challenges associated such as poor aqueous solubility, high metabolism, rapid excretion and infelicitous molecular size resulting in poor systemic availability, etc. Consequently, to surmount these major obstacles, the nano-technological intervention plays a consequential role in converting this old-age remedy to an age-old solution with amended curative index. A wellformulated nano approach leads to an enhancement of bioavailability and bioactivity by reducing the particle size, modification of surfaces, and entrapment of curcumin with different nanocarriers. The avenue of nanotechnology could improve the perspective for medical patients with serious 
illnesses or injuries. Nanotechnology itself revolutionizes many different aspects of our lives and also proven to be a wondrous and majestic engenderment in near future.

\section{Abbreviations}

THC, Tetrahydrocurcumin, HHC, Hexahydrocurcumin, TPA, 12-O-tetradecanoylphorbol-13-acetate, PLGA, Poly (lactic-co-glycolic acid), PEG, Polyethylene glycol, F-CM-HSANPs, folate-conjugated, curcuminloaded human serum albumin nanoparticles, DPPC, 1,2 dipalmitoyl-sn-glycero-3-phosphocholine, IL-6, Interleukin-6, NF- kB, Nuclear Factor kappa-b, COX2, Cyclooxygenase 2, TNF- $\alpha$, Tumor necrosis factoralpha, CGRP, Calcitonin Gene Related Peptide, MCP-1, Monocyte Chemo attractant Protein-1, SOCS 1, Suppressor of cytokine signaling 1, JAK2/STAT3, Janus kinase 2/ Signal transducer and activator of Transcription 3, ROS, Reactive oxygen species, M-EPL, Modified E-polylysine, DPPC, dipalmitoyl-sn-glycero-3-phosphocholine, IAV, Influenza avian virus, HPV, Human papilloma virus, HSV1, Herpes simplex virus type 1, HCV, Hepatitis C virus, MMP-2, Matrix metalloproteinase-2; MMP-9, Matrix metalloproteinase- 9 , TGF- $\beta$, Transforming growth factorbeta; SHP1, Src homology phosphatase-1; PIAS, Protein inhibitor of activated signal (Protein); XIAP, X-linked inhibitor of apoptosis protein.

\section{ACKNOWLEDGMENTS}

This research was supported by Basic Science Research Program through the National Research Foundation of Korea (NRF) funded by the Ministry of Education (2016R1 A6A1A03012862). Hence the authors are thankful to this organization.

\section{CONFLICTS OF INTEREST}

The authors declare no conflicts of interests.

\section{REFERENCES}

1. Cragg GM, Newman DJ. Medicinals for the Millennia. Ann N Y Acad Sci. 2001; 953:3-25.

2. Schmidt BM, Ribnicky DM, Lipsky PE, Raskin I. Revisiting the ancient concept of botanical therapeutics. Nat Chem Biol. 2007; 3:360-66.

3. Duvoix A, Blasius R, Delhalle S, Schnekenburger M, Morceau F, Henry E, Dicato M, Diederich M. Chemopreventive and therapeutic effects of curcumin. Cancer Lett. 2005; 223:181-90.

4. Li HL, Liu C, de Couto G, Ouzounian M, Sun M, Wang AB, Huang Y, He CW, Shi Y, Chen X, Nghiem MP, Liu Y, Chen $\mathrm{M}$, et al. Curcumin prevents and reverses murine cardiac hypertrophy. J Clin Invest. 2008; 118:879-93.
5. Tyagi AK, Prasad S, Yuan W, Li S, Aggarwal BB. Identification of a novel compound ( $\beta$-sesquiphellandrene) from turmeric (Curcuma longa) with anticancer potential: comparison with curcumin. Invest New Drugs. 2015; 33:1175-86.

6. Milobedeska J, Kostanecki V, Lampe V. Structure of curcumin. Ber Dtsch Chem Ges. 1910; 43:2163-2170.

7. Jovanovic SV, Steenken S, Boone CW, Simic MG. H-atom transfer is a preferred antioxidant mechanism of curcumin. J Am Chem Soc. 1999; 121:9677-81.

8. Sreejayan N, Rao MN. Free radical scavenging activity of curcuminoids. Arzneimittelforschung. 1996; 46:169-71.

9. Hoehle SI, Pfeiffer E, Sólyom AM, Metzler M. Metabolism of curcuminoids in tissue slices and subcellular fractions from rat liver. J Agric Food Chem. 2006; 54:756-64.

10. Priyadarsini KI. Photophysics photochemistry and photobiology of curcumin: Studies from organic solutions bio-mimetics and living cells. J Photochem Photobiol. 2009; 10:81-95.

11. Pizzo P, Scapin C, Vitadello M, Florean C, Gorza L. Grp94 acts as a mediator of curcumin-induced antioxidant defence in myogenic cells. J Cell Mol Med. 2010; 14:970-81.

12. Sugiyama Y, Kawakishi S, Osawa T. Involvement of the beta-diketone moiety in the antioxidative mechanism of tetrahydrocurcumin. Biochem Pharmacol. 1996; 52:519-25.

13. Lee YK, Lee WS, Hwang JT, Kwon DY, Surh YJ, Park OJ. Curcumin exerts antidifferentiation effect through AMPKalpha-PPAR- $\gamma$ in 3T3-L1 adipocytes and antiproliferatory effect through AMPKalpha-COX-2 in cancer cells. J Agric Food Chem. 2009; 57:305-10.

14. De R, Kundu P, Swarnakar S, Ramamurthy T, Chowdhury A, Nair GB, Mukhopadhyay AK. Antimicrobial activity of curcumin against Helicobacter pylori isolates from India and during infections in mice. Antimicrob Agents Chemother. 2009; 53:1592-97.

15. Srimal RC, Dhawan BN. Pharmacology of diferuloyl methane (curcumin), a non-steroidal anti-inflammatory agent. J Pharm Pharmacol. 1973; 25:447-52.

16. Aggarwal BB, Harikumar KB. Potential therapeutic effects of curcumin, the anti-inflammatory agent, against neurodegenerative, cardiovascular, pulmonary, metabolic, autoimmune and neoplastic diseases. Int $\mathrm{J}$ Biochem Cell Biol. 2009; 41:40-59.

17. Morimoto T, Sunagawa Y, Kawamura T, Takaya T, Wada H, Nagasawa A, Komeda M, Fujita M, Shimatsu A, Kita T, Hasegawa K. The dietary compound curcumin inhibits p300 histone acetyltransferase activity and prevents heart failure in rats. J Clin Invest. 2008; 118:868-78.

18. Wang Y, Lu Z, Wu H, Lv F. Study on the antibiotic activity of microcapsule curcumin against foodborne pathogens. Int J Food Microbiol. 2009; 136:71-74.

19. Sahni JK, Baboota S, Ali J. Promising role of nanopharmaceuticals in drug delivery. Pharm Times. 2011; 43:16-18. 
20. Wang D, Veena MS, Stevenson K, Tang C, Ho B, Suh JD, Duarte VM, Faull KF, Mehta K, Srivatsan ES, Wang MB. Liposome-encapsulated curcumin suppresses growth of head and neck squamous cell carcinoma in vitro and in xenografts through the inhibition of nuclear factor kappaB by an AKT-independent pathway. Clin Cancer Res. 2008; 14:6228-36.

21. Das RK, Kasoju N, Bora U. Encapsulation of curcumin in alginate-chitosan-pluronic composite nanoparticles for delivery to cancer cells. Nanomedicine (Lond). 2010; 6:153-60.

22. Gupta V, Aseh A, Ríos CN, Aggarwal BB, Mathur AB. Fabrication and characterization of silk fibroinderived curcumin nanoparticles for cancer therapy. Int $\mathrm{J}$ Nanomedicine. 2009; 4:115-22.

23. Patra S, Roy E, Karfa P, Kumar S, Madhuri R, Sharma PK. Dual-responsive polymer coated superparamagnetic nanoparticle for targeted drug delivery and hyperthermia treatment. ACS Appl Mater Interfaces. 2015; 7:9235-46.

24. Hu L, Kong D, Hu Q, Gao N, Pang S. Evaluation of highperformance curcumin nanocrystals for pulmonary drug delivery both in vitro and in vivo. Nanoscale Res Lett. 2015; $10: 381$.

25. Russo M, Spagnuolo C, Tedesco I, Bilotto S, Russo GL. The flavonoid quercetin in disease prevention and therapy: facts and fancies. Biochem Pharmacol. 2012; 83:6-15.

26. Zhang L, Zhu W, Yang C, Guo H, Yu A, Ji J, Gao Y, Sun M, Zhai G. A novel folate-modified self-microemulsifying drug delivery system of curcumin for colon targeting. Int $\mathrm{J}$ Nanomedicine. 2012; 7:151-62.

27. Tønnesen HH, Karlsen J. Studies on curcumin and curcuminoids. VI. Kinetics of curcumin degradation in aqueous solution. Z Lebensm Unters Forsch. 1985; 180:402-04.

28. Palanikumar L, Panneerselvam N. Curcumin: A putative chemopreventive agent. J Life Sci. 2009; 3:47-53.

29. Lao CD, Ruffin MT 4th, Normolle D, Heath DD, Murray SI, Bailey JM, Boggs ME, Crowell J, Rock CL, Brenner DE. Dose escalation of a curcuminoid formulation. BMC Complement Altern Med. 2006; 6:10.

30. la Porte C, Voduc N, Zhang G, Seguin I, Tardiff D, Singhal N, Cameron DW. Steady-State pharmacokinetics and tolerability of trans-resveratrol $2000 \mathrm{mg}$ twice daily with food, quercetin and alcohol (ethanol) in healthy human subjects. Clin Pharmacokinet. 2010; 49:449-54.

31. Shehzad A, Wahid F, Lee YS. Curcumin in cancer chemoprevention: molecular targets, pharmacokinetics, bioavailability, and clinical trials. Arch Pharm (Weinheim). 2010; 343:489-99.

32. Wahlström B, Blennow G. A study on the fate of curcumin in the rat. Acta Pharmacol Toxicol (Copenh). 1978; 43:86-92.

33. Holder GM, Plummer JL, Ryan AJ. The metabolism and excretion of curcumin (1,7-bis-(4-hydroxy-3- methoxyphenyl)-1,6-heptadiene-3,5-dione) in the rat. Xenobiotica. 1978; 8:761-68.

34. Ireson $\mathrm{C}$, Orr $\mathrm{S}$, Jones $\mathrm{DJ}$, Verschoyle R, Lim CK, Luo JL, Howells L, Plummer S, Jukes R, Williams M, Steward WP, Gescher A. Characterization of metabolites of the chemopreventive agent curcumin in human and rat hepatocytes and in the rat in vivo, and evaluation of their ability to inhibit phorbol ester-induced prostaglandin E2 production. Cancer Res. 2001; 61:1058-64.

35. Ireson CR, Jones DJ, Orr S, Coughtrie MW, Boocock DJ, Williams ML, Farmer PB, Steward WP, Gescher AJ. Metabolism of the cancer chemopreventive agent curcumin in human and rat intestine. Cancer Epidemiol Biomarkers Prev. 2002; 11:105-11.

36. Ravindranath V, Chandrasekhara N. Metabolism of curcumin—studies with $[3 \mathrm{H}]$ curcumin. Toxicology. 1981$1982 ; 22: 337-44$.

37. Pan MH, Huang TM, Lin JK. Biotransformation of curcumin through reduction and glucuronidation in mice. Drug Metab Dispos. 1999; 27:486-94.

38. Hatcher H, Planalp R, Cho J, Torti FM, Torti SV. Curcumin: from ancient medicine to current clinical trials. Cell Mol Life Sci. 2008; 65:1631-52.

39. Anand P, Kunnumakkara AB, Newman RA, Aggarwal BB. Bioavailability of curcumin: problems and promises. Mol Pharm. 2007; 4:807-18.

40. Prasad S, Tyagi AK, Aggarwal BB. Recent developments in delivery, bioavailability, absorption and metabolism of curcumin: the golden pigment from golden spice. Cancer Res Treat. 2014; 46:2-18.

41. Cheng AL, Hsu CH, Lin JK, Hsu MM, Ho YF, Shen TS, Ko JY, Lin JT, Lin BR, Ming-Shiang W, Yu HS, Jee SH, Chen GS, et al. Phase I clinical trial of curcumin, a chemopreventive agent, in patients with high-risk or premalignant lesions. Anticancer Res. 2001; 21:2895-900.

42. Carroll RE. Colon preparation for magnification endoscopy: a rapid novel approach. Endoscopy. 2004; 36:609-11.

43. Kim SG, Veena MS, Basak SK, Han E, Tajima T, Gjertson DW, Starr J, Eidelman O, Pollard HB, Srivastava M, Srivatsan ES, Wang MB. Curcumin treatment suppresses IKK $\beta$ kinase activity of salivary cells of patients with head and neck cancer: a pilot study. Clin Cancer Res. 2011; 17:5953-61.

44. Epelbaum R, Schaffer M, Vizel B, Badmaev V, Bar-Sela G. Curcumin and gemcitabine in patients with advanced pancreatic cancer. Nutr Cancer. 2010; 62:1137-41.

45. Bayet-Robert M, Kwiatowski F, Leheurteur M, Gachon F, Planchat E, Abrial C, Mouret-Reynier MA, Durando $\mathrm{X}$, Barthomeuf C, Chollet P. Phase I dose escalation trial of docetaxel plus curcumin in patients with advanced and metastatic breast cancer. Cancer Biol Ther. 2010; 9:8-14.

46. Ghalaut VS, Sangwan L, Dahiya K, Ghalaut PS, Dhankhar R, Saharan R. Effect of imatinib therapy with and without 
turmeric powder on nitric oxide levels in chronic myeloid leukemia. J Oncol Pharm Pract. 2012; 18:186-90.

47. Shang L, Nienhaus K, Nienhaus GU. Engineered nanoparticles interacting with cells: size matters. J Nanobiotechnology. 2014; 12:5.

48. Powers KW, Palazuelos M, Moudgil BM, Roberts SM. Characterization of the size, shape, and state of dispersion of nanoparticles for toxicological studies. Nanotoxicology. 2007; 1:42-51.

49. Shinde Patil VR, Campbell CJ, Yun YH, Slack SM, Goetz DJ. Particle diameter influences adhesion under flow. Biophys J. 2001; 80:1733-43.

50. Champion JA, Walker A, Mitragotri S. Role of particle size in phagocytosis of polymeric microspheres. Pharm Res. 2008; 25:1815-21.

51. Gratton SE, Ropp PA, Pohlhaus PD, Luft JC, Madden VJ, Napier ME, DeSimone JM. The effect of particle design on cellular internalization pathways. Proc Natl Acad Sci USA. 2008; 105:11613-18.

52. Foged C, Brodin B, Frokjaer S, Sundblad A. Particle size and surface charge affect particle uptake by human dendritic cells in an in vitro model. Int J Pharm. 2005; 298:315-22.

53. Liu CH, Chang FY. Development and characterization of eucalyptol microemulsions for topic delivery of curcumin. Chem Pharm Bull. 2011; 59:172-8.

54. Setthacheewakul S, Mahattanadul S, Phadoongsombut N, Pichayakorn W, Wiwattanapatapee R. Development and evaluation of self-microemulsifying liquid and pellet formulations of curcumin, and absorption studies in rats. Eur J Pharm Biopharm. 2010; 76:475-85.

55. Alexis F, Pridgen E, Molnar LK, Farokhzad OC. Factors affecting the clearance and biodistribution of polymeric nanoparticles. Mol Pharm. 2008; 5:505-15.

56. Petros RA, DeSimone JM. Strategies in the design of nanoparticles for therapeutic applications. Nat Rev Drug Discov. 2010; 9:615-27.

57. Sharma G, Valenta DT, Altman Y, Harvey S, Xie H, Mitragotri S, Smith JW. Polymer particle shape independently influences binding and internalization by macrophages. J Control Release. 2010; 147:408-12.

58. Geng YA, Dalhaimer P, Cai S, Tsai R, Tewari M, Minko T, Discher DE. Shape effects of filaments versus spherical particles in flow and drug delivery. Nat Nanotechnol. 2007; 2:249-55.

59. Chithrani BD, Ghazani AA, Chan WC. Determining the size and shape dependence of gold nanoparticle uptake into mammalian cells. Nano Lett. 2006; 6:662-68.

60. Barua S, Yoo JW, Kolhar P, Wakankar A, Gokarn YR, Mitragotri S. Particle shape enhances specificity of antibody-displaying nanoparticles. Proc Natl Acad Sci USA. 2013; 110:3270-75.

61. Verwey EJW, Overbeek JThG. Theory of the Stability of Lyophobic Colloids: The Interaction of Sol Particles
Having an Electric Double Layer. Elsevier; Amsterdam. 1948.

62. Derjaguin B, Landau L. Theory of the Stability of Strongly Charged Lyophobic Sols and of the Adhesion of Strongly Charged Particles in Solutions of ElectrolytesProg Surf Sci. 1993; 43:30-59.

63. Muller KH, Motskin M, Philpott AJ, Routh AF, Shanahan CM, Duer MJ, Skepper JN. The effect of particle agglomeration on the formation of a surface-connected compartment induced by hydroxyapatite nanoparticles in human monocyte-derived macrophages. Biomaterials. 2014; 35:1074-88.

64. Yang ST, Wang X, Jia G, Gu Y, Wang T, Nie H, Ge C, Wang H, Liu Y. Long-term accumulation and low toxicity of single-walled carbon nanotubes in intravenously exposed mice. Toxicol Lett. 2008; 181:182-9.

65. Wick P, Manser P, Limbach LK, Dettlaff-Weglikowska U, Krumeich F, Roth S, Stark WJ, Bruinink A. The degree and kind of agglomeration affect carbon nanotube cytotoxicity. Toxicol Lett. 2007; 168:121-31.

66. Shahbazi MA, Herranz B, Santos HA. Nanostructured porous Si-based nanoparticles for targeted drug delivery. Biomatter. 2012; 2:296-312.

67. Gupta AK, Gupta M. Cytotoxicity suppression and cellular uptake enhancement of surface modified magnetic nanoparticles. Biomaterials. 2005; 26:1565-73.

68. Doggui S, Sahni JK, Arseneault M, Dao L, Ramassamy C. Neuronal uptake and neuroprotective effect of curcuminloaded PLGA nanoparticles on the human SK-N-SH cell line. J Alzheimer's Dis. 2012; 30:377-92.

69. Tiwari SK, Agarwal S, Seth B, Yadav A, Nair S, Bhatnagar P, Karmakar M, Kumari M, Chauhan LK, Patel DK, Srivastava V, Singh D, Gupta SK, et al. Curcumin-loaded nanoparticles potently induce adult neurogenesis and reverse cognitive deficits in Alzheimer's disease model via canonical Wnt/ $\beta$-catenin pathway. ACS Nano. 2013; 8:76-103.

70. Ray B, Bisht S, Maitra A, Maitra A, Lahiri DK. Neuroprotective and neurorescue effects of a novel polymeric nanoparticle formulation of curcumin (NanoCurc ${ }^{\mathrm{TM}}$ ) in the neuronal cell culture and animal model: implications for Alzheimer's disease. J Alzheimer's Dis. 2011; 23:61-77.

71. Sahub C, Tumcharern G, Chirawatkul P, Ruangpornvisuti V, Ekgasit S, Wanichweacharungruang S, Tuntulani T, Palaga T, Tomapatanaget B. Self-assembly of Gd3+/SDS/HEPES complex and curcumin entrapment for enhanced stability, fluorescence image in cellular system. Colloids Surf B Biointerfaces. 2017; 13:156:254-261.

72. Mulik RS, Monkkonen J, Juvonen RO, Mahadik KR, Paradkar AR. ApoE3 mediated poly (butyl) cyanoacrylate nanoparticles containing curcumin: study of enhanced activity of curcumin against beta amyloid induced 
cytotoxicity using in vitro cell culture model. Mol Pharma. 2010; 7:815-25.

73. Aminirad A, Mousavi SE, Fakhraei N, Mousavi SM, Rezayat SM. The role of nitric oxide in anticonvulsant effect of nanocurcumine on pentylenetetrazole-induced seizure in mice. Neurosci Lett. 2017; 651:226-231.

74. Yallapu MM, Gupta BK, Jaggi M, Chauhan SC. Fabrication of curcumin encapsulated PLGA nanoparticles for improved therapeutic effects in metastatic cancer cells. Adv Colloid Interface Sci. 2010; 351:19-29.

75. Yallapu MM, Ebeling MC, Chauhan N, Jaggi M, Chauhan $\mathrm{SC}$. Interaction of curcumin nanoformulations with human plasma proteins and erythrocytes. Int J Nanomedicine. 2011; 6:2779-90.

76. Yallapu MM, Othman SF, Curtis ET, Gupta BK, Jaggi M, Chauhan SC. Multi-functional magnetic nanoparticles for magnetic resonance imaging and cancer therapy. Biomaterials. 2011; 32:1890-905.

77. Zhu XQ, Sun M, Zhu FP, Ding TT, Zhai YJ, Zhai GX. [Preparation and characterization of curcumin polybutylcyanoacrylate nanoparticles]. [Article in Chinese]. Zhong Yao Cai. 2010; 33:797-801.

78. Marslin G, Sarmento BF, Franklin G, Martins JA, Silva CJ, Gomes AF, Sárria MP, Coutinho OM, Dias AC. Curcumin Encapsulated into Methoxy Poly (Ethylene Glycol) Poly ( $\varepsilon$-Caprolactone) Nanoparticles Increases Cellular Uptake and Neuroprotective Effect in Glioma Cells. Planta Med. 2017; 83:434-44.

79. Thangapazham RL, Puri A, Tele S, Blumenthal R, Maheshwari RK. Evaluation of a nanotechnology-based carrier for delivery of curcumin in prostate cancer cells Int J Oncol. 2008; 32:1119-24.

80. Gou M, Men K, Shi H, Xiang M, Zhang J, Song J, Long J, Wan Y, Luo F, Zhao X, Qian Z. Curcumin-loaded biodegradable polymeric micelles for colon cancer therapy in vitro and in vivo. Nanoscale. 2011; 3:1558-67.

81. Sun M, Gao Y, Guo C, Cao F, Song Z, Xi Y, Yu A, Li A, Zhai G. Enhancement of transport of curcumin to brain in mice by poly (n-butylcyanoacrylate) nanoparticle. Nanopart Res. 2010; 12:3111-22.

82. Ganta S, Amiji M. Coadministration of paclitaxel and curcumin in nanoemulsion formulations to overcome multidrug resistance in tumor cells. Mol Pharm. 2009; 6:928-39.

83. Misra R, Sahoo SK. Coformulation of doxorubicin and curcumin in poly ( $\mathrm{D}, \mathrm{L}-$-lactide-co-glycolide) nanoparticles suppresses the development of multidrug resistance in K562 cells. Mol Pharm. 2011; 8:852-66.

84. Li X, Chen S, Zhang B, Li M, Diao K, Zhang Z, Li J, Xu Y, Wang X, Chen H. In situ injectable nano-composite hydrogel composed of curcumin, N, O-carboxymethyl chitosan and oxidized alginate for wound healing application. Int J Pharm. 2012; 437:110-9.

85. Mangalathillam S, Rejinold NS, Nair A, Lakshmanan VK, Nair SV, Jayakumar R. Curcumin loaded chitin nanogels for skin cancer treatment via the transdermal route. Nanoscale. 2012; 4:239-50.

86. Onoue S, Takahashi H, Kawabata Y, Seto Y, Hatanaka J, Timmermann B, Yamada S. Formulation design and photochemical studies on nanocrystal solid dispersion of curcumin with improved oral bioavailability. J Pharm Sci. 2010; 99:1871-81.

87. Sasaki H, Sunagawa Y, Takahashi K, Imaizumi A, Fukuda H, Hashimoto T, Wada H, Katanasaka Y, Kakeya H, Fujita M, Hasegawa K. Innovative preparation of curcumin for improved oral bioavailability. Biol Pharm Bull. 2011; 34:660-5.

88. Garodia P, Ichikawa H, Malani N, Sethi G, Aggarwal BB. From ancient medicine to modern medicine: ayurvedic concepts of health and their role in inflammation and cancer. J Soc Integr Oncol. 2007; 5:25-37.

89. Jourghanian P, Ghaffari S, Ardjmand M, Haghighat S, Mohammadnejad M. Sustained release Curcumin loaded Solid Lipid Nanoparticles. Adv Pharm Bull. 2016; 6:17.

90. Song Z, Lu Y, Zhang X, Wang H, Han J, Dong C. Novel curcumin-loaded human serum albumin nanoparticles surface functionalized with folate: characterization and in vitro/vivo evaluation. ¡Drug Des Devel Ther. 2016; 10:2643.

91. Darandale SS, Vavia PR. Cyclodextrin-based nanosponges of curcumin: formulation and physicochemical characterization. J Incl Phenom Macrocycl Chem. 2013; 75:315-22.

92. Kundu P, Mohanty C, Sahoo SK. Antiglioma activity of curcumin-loaded lipid nanoparticles and its enhanced bioavailability in brain tissue for effective glioblastoma therapy. Acta Biomater. 2012; 8:2670-87.

93. Bisht S, Feldmann G, Soni S, Ravi R, Karikar C, Maitra A, Maitra A. Polymeric nanoparticle-encapsulated curcumin ("nanocurcumin"): a novel strategy for human cancer therapy. J Nanobiotechnol. 2007; 5:3.

94. Gupta SC, Patchva S, Aggarwal BB. Therapeutic roles of curcumin: lessons learned from clinical trials. AAPS J. 2013; 15:195-218.

95. Magesh S, Chen Y, Hu L. Small molecule modulators of Keap1-Nrf2-ARE pathway as potential preventive and therapeutic agents. Med Res Rev. 2012; 32:687-726.

96. Lee KC, Maturo C, Rodriguez R, Nguyen HL, Shorr R. Nanomedicine-Nanoemulsion Formulation Improves Safety and Efficacy of the Anti-Cancer Drug Paclitaxel According to Preclinical Assessment. J Nanosci Nanotechnol. 2011; 11:6642-56.

97. Hanai H, Sugimoto K. Curcumin has bright prospects for the treatment of inflammatory bowel disease. Curr Pharm Des. 2009; 15:2087-94.

98. Al-Rohaimi AH. Comparative anti-inflammatory potential of crystalline and amorphous nano curcumin in topical drug delivery. J Oleo Sci. 2015; 64:27-40.

99. Aggarwal BB, Yuan W, Li S, Gupta SC. Curcuminfree turmeric exhibits anti-inflammatory and anticancer 
activities: Identification of novel components of turmeric. Mol Nutr Food Res. 2013; 57:1529-42.

100. Jurenka JS. Anti-inflammatory properties of curcumin, a major constituent of Curcuma longa: a review of preclinical and clinical research. Altern Med Rev. 2009; 14:141-53.

101. Kurd SK, Smith N, VanVoorhees A, Troxel AB, Badmaev V, Seykora JT, Gelfand JM. Oral curcumin in the treatment of moderate to severe psoriasis vulgaris: A prospective clinical trial. J Am Acad Dermatol. 2008; 58:625-31.

102. Satoskar RR, Shah SJ, Shenoy SG. Evaluation of antiinflammatory property of curcumin (diferuloyl methane) in patients with postoperative inflammation Int J Clin Pharmacol Ther Toxicol. 1986; 24:651.

103. Oppenheimer A. Turmeric (curcumin) in biliary diseases. Lancet. 1937; 229:619-21.

104. Moreillon JJ, Bowden RG, Deike E, Griggs J, Wilson R, Shelmadine B, Cooke M, Beaujean A. The use of an antiinflammatory supplement in patients with chronic kidney disease. J Complement Integr Med. 2013; 10:143-52.

105. Zhang X, Wu J, Ye B, Wang Q, Xie X, Shen H. Protective effect of curcumin on TNBS-induced intestinal inflammation is mediated through the JAK/STAT pathway. BMC Complement Altern Med. 2016; 16:299.

106. Yadav VR, Prasad S, Kannappan R, Ravindran J, Chaturvedi MM, Vaahtera L, Parkkinen J, Aggarwal BB. Cyclodextrincomplexed curcumin exhibits anti-inflammatory and antiproliferative activities superior to those of curcumin through higher cellular uptake. Biochem Pharmacol. 2010; 80:1021-32.

107. Ghosh M, Sodhi SS, Kim JH, Kim NE, Mongre RK, Sharma N, Kim SW, Oh SJ, Pulicherla KK, Jeong, DK. An integrated in silico approach for the structural and functional exploration of Lipocalin 2 and its functional insights with metalloproteinase 9 and lipoprotein receptor-related protein 2. Appl Biochem. Biotechnol. 2015; 176:712-729.

108. Tønnesen HH, Arrieta AF, Lerner D. Studies on curcumin and curcuminoids. XXIV: Characterization of the spectroscopic properties of the naturally occurring curcuminoids and selected derivatives. Pharmazie. 1995; 50:689-93.

109. Vajragupta O, Boonchoong $\mathrm{P}$, Watanabe H, Tohda M, Kummasud N, Sumanont Y. Manganese complexes of curcumin and its derivatives: evaluation for the radical scavenging ability and neuroprotective activity. Free Radic Biol Med. 2003; 35:1632-44.

110. Venkatesan P, Rao MN. Structure-activity relationships for the inhibition of lipid peroxidation and the scavenging of free radicals by synthetic symmetrical curcumin analogues. J Pharm Pharmacol. 2000; 52:1123-8.

111. González-Reyes S, Guzmán-Beltrán S, Medina-Campos ON, Pedraza-Chaverri J. Curcumin pretreatment induces Nrf2 and an antioxidant response and prevents hemininduced toxicity in primary cultures of cerebellar granule neurons of rats. Oxid Med Cell Longev. 2013; 2013.
112. Mishra B, Indira Priyadarsini K, Bhide MK, Kadam RM, Mohan H. Reactions of superoxide radicals with curcumin: probable mechanisms by optical spectroscopy and EPR. Free Radic Res. 2004; 38:355-62.

113. Joe B, Lokesh BR. Role of capsaicin, curcumin and dietary $\mathrm{n}-3$ fatty acids in lowering the generation of reactive oxygen species in rat peritoneal macrophages. Biochim Biophys Acta. 1994; 1224:255-63.

114. He ZY, Shi CB, Wen H, Li FL, Wang BL, Wang J. Upregulation of p53 expression in patients with colorectal cancer by administration of curcumin. Cancer Invest. 2011; 29:208-13.

115. Yu H, Li J, Shi K, Huang Q. Structure of modified $\varepsilon$-polylysine micelles and their application in improving cellular antioxidant activity of curcuminoids. Food Funct. $2011 ; 2: 373-80$.

116. Tyagi P, Singh M, Kumari H, Kumari A, Mukhopadhyay $\mathrm{K}$. Bactericidal activity of curcumin I is associated with damaging of bacterial membrane. PLoS One. 2015; 10:e 0121313.

117. Negi PS, Jayaprakasha GK, Jagan Mohan Rao L, Sakariah KK. Antibacterial activity of turmeric oil: a byproduct from curcumin manufacture. J Agric Food Chem. 1999; 47:4297-300.

118. Pérez-Lara A, Ausili A, Aranda FJ, Godos AD, Torrecillas A, Corbalán-García S, Gómez-Fernández JC. Curcumin disorders 1,2-dipalmitoyl-sn-glycero-3phosphocholine membranes and favors the formation of nonlamellar structures by 1,2-dielaidoyl-sn-glycero-3phosphoethanolamine. J Phys Chem B. 2010; 114:9778-86.

119. Lüer S, Troller R, Aebi C. Antibacterial and antiinflammatory kinetics of curcumin as a potential antimucositis agent in cancer patients. Nutr Cancer. 2012; 64:975-81.

120. Rai D, Singh JK, Roy N, Panda D. Curcumin inhibits FtsZ assembly: an attractive mechanism for its antibacterial activity. Biochem J. 2008; 410:147-55.

121. Gera M, Kumar R, Jain VK, Suman. Preparation of a Novel Nanocurcumin Loaded Drug Releasing Medicated Patch with Enhanced Bioactivity against Microbes. Adv Sci Eng Med. 2015; 7:485-91.

122. Vimala K, Mohan YM, Sivudu KS, Varaprasad K, Ravindra S, Reddy NN, Padma Y, Sreedhar B, MohanaRaju K. Fabrication of porous chitosan films impregnated with silver nanoparticles: a facile approach for superior antibacterial application. Colloids Surf B Biointerfaces. 2010; 76:248-58.

123. Wang YF, Shao JJ, Zhou CH, Zhang DL, Bie XM, Lv FX, Zhang C, Lu ZX. Food preservation effects of curcumin microcapsules. Food Control. 2012; 27:113-7.

124. Sharma M, Manoharlal R, Puri N, Prasad R. Antifungal curcumin induces reactive oxygen species and triggers an early apoptosis but prevents hyphae development by targeting the global repressor TUP1 in Candida albicans. Biosci Rep. 2010; 30:391-404. 
125. Zandi K, Ramedani E, Mohammadi K, Tajbakhsh S, Deilami I, Rastian Z, Fouladvand M, Yousefi F, Farshadpour F. Evaluation of antiviral activities of curcumin derivatives against HSV-1 in Vero cell line. Nat Prod Commun. 2010; 5:1935-8.

126. Kim K, Kim KH, Kim HY, Cho HK, Sakamoto N, Cheong J. Curcumin inhibits hepatitis $\mathrm{C}$ virus replication via suppressing the Akt-SREBP-1 pathway. FEBS Lett. 2010; 584:707-12.

127. Singh AK, Sharma N, Ghosh M, Park YH, Jeong DK. Emerging importance of dietary phytochemicals in fight against cancer: role in targeting cancer stem cells. rit Rev Food Sci Nutr. 2017; 57:3449-3463.

128. Zaman MS, Chauhan N, Yallapu MM, Gara RK, Maher DM, Kumari S, Sikander M, Khan S, Zafar N, Jaggi M, Chauhan SC. Curcumin nanoformulation for cervical cancer treatment. Sci Rep. 2016; 6:20051.

129. Mukerjee A, Vishwanatha JK. Formulation, characterization and evaluation of curcumin-loaded PLGA nanospheres for cancer therapy. Anticancer Res. 2009; 29:3867-75.

130. Mulik RS, Mönkkönen J, Juvonen RO, Mahadik KR, Paradkar AR. Transferrin mediated solid lipid nanoparticles containing curcumin: enhanced in vitro anticancer activity by induction of apoptosis. Int J Pharm. 2010; 398:190-203.

131. Wilken R, Veena MS, Wang MB, Srivatsan ES. Curcumin: A review of anti-cancer properties and therapeutic activity in head and neck squamous cell carcinoma. Mol Cancer. 2011; 10:12.

132. Singh S, Aggarwal BB. Activation of transcription factor NF-B is suppressed by curcumin (diferuloylmethane). J Biol Chem. 1995; 270:24995-25000.

133. Shanmugam MK, Rane G, Kanchi MM, Arfuso F, Chinnathambi A, Zayed ME, Alharbi SA, Tan BK, Kumar AP, Sethi G. The multifaceted role of curcumin in cancer prevention and treatment. Molecules. 2015; 20:2728-69.

134. Kunnumakkara AB, Anand P, Aggarwal BB. Curcumin inhibits proliferation, invasion, angiogenesis and metastasis of different cancers through interaction with multiple cell signaling proteins. Cancer Lett. 2008; 269:199-225.

135. Chadalapaka G, Jutooru I, Chintharlapalli S, Papineni S, Smith R 3rd, Li X, Safe S. Curcumin decreases specificity protein expression in bladder cancer cells. Cancer Res. 2008; 68:5345-54.

136. Jutooru I, Chadalapaka G, Lei P, Safe S. Inhibition of NFkB and pancreatic cancer cell and tumor growth by curcumin is dependent on specificity protein down-regulation. J Biol Chem. 2010; 285:25332-44.

137. Khar A, Ali AM, Pardhasaradhi BV, Begum Z, Anjum R. Antitumor activity of curcumin is mediated through the induction of apoptosis in AK-5 tumor cells. FEBS Lett. 1999; 445:165-8.
138. Xie M, Fan D, Zhao Z, Li Z, Li G, Chen Y, He X, Chen A, Li J, Lin X, Zhi M, Li Y, Lan P. Nano-curcumin prepared via supercritical: Improved anti-bacterial, anti-oxidant and anti-cancer efficacy. Int J Pharm. 2015; 496:732-40.

139. Goel A, Aggarwal BB. Curcumin, the golden spice from Indian saffron, is a chemosensitizer and radiosensitizer for tumors and chemoprotector and radioprotector for normal organs. Nutr Cancer. 2010; 62:919-30.

140. Lochter A, Bissell MJ. An odyssey from breast to bone: multi-step control of mammary metastases and osteolysis by matrix metalloproteinases. APMIS. 1999; 107:128-36.

141. Menon LG, Kuttan R, Kuttan G. Inhibition of lung metastasis in mice induced by B16F10 melanoma cells by polyphenolic compounds. Cancer Lett. 1995; 95:221-5.

142. Saydmohammed M, Joseph D, Syed V. Curcumin suppresses constitutive activation of STAT-3 by upregulating protein inhibitor of activated STAT-3 (PIAS-3) in ovarian and endometrial cancer cells. J Cell Biochem. 2010; 110:447-56.

143. Guo F, Xu CJ. [Progress on the study of mechanism of the direct action of TCM bioactive components on ovarian cancer]. [Article in Chinese]. Zhongguo Zhong Xi Yi Jie He Za Zhi. 2005; 25:1140-4.

144. Nakagawa-Goto K, Yamada K, Nakamura S, Chen TH, Chiang PC, Bastow KF, Wang SC, Spohn B, Hung MC, Lee FY, Lee FC, Lee KH. Antitumor agents. 258. Syntheses and evaluation of dietary antioxidant - taxoid conjugates as novel cytotoxic agents. Bioorg Med Chem Lett. 2007; 17:5204-09.

145. Lin YG, Kunnumakkara AB, Nair A, Merritt WM, Han LY, Armaiz-Pena GN, Kamat AA, Spannuth WA, Gershenson DM, Lutgendorf SK, Aggarwal BB, Sood AK. Curcumin inhibits tumor growth and angiogenesis in ovarian carcinoma by targeting the nuclear factor- $\kappa \mathrm{B}$ pathway. Clin Cancer Res. 2007; 13:3423-30.

146. Ramamoorthi G, Sivalingam N. Molecular mechanism of TGF- $\beta$ signaling pathway in colon carcinogenesis and status of curcumin as chemopreventive strategy. Tumour Biol. 2014; 35:7295-305.

147. Toden S, Okugawa Y, Jascur T, Wodarz D, Komarova NL, Buhrmann C, Shakibaei M, Boland CR, Goel A. Curcumin mediates chemosensitization to 5-fluorouracil through miRNA-induced suppression of epithelial-tomesenchymal transition in chemoresistant colorectal cancer. Carcinogenesis. 2015; 36:355-67.

148. Basniwal RK, Khosla R, Jain N. Improving the anticancer activity of curcumin using nanocurcumin dispersion in water. Nutr Cancer. 2014; 66:1015-22. 